\title{
Antitumor Activity of Resveratrol in Combination with Selenium in Ehrlich Ascites Carcinoma Bearing and/or Irradiated Mice
}

\author{
Mohamed R. Mohamed ${ }^{1 *}$, Soheir A. Osman ${ }^{2}$, Neama M. El Fateh ${ }^{2}$ and Mahmoud M. Refaat ${ }^{2}$ \\ ${ }^{1}$ Department of Biochemistry, Faculty of Science, Ain Shams University, 11566 Abbassia, Cairo, Egypt, \\ ${ }^{2}$ Radiation Biology Department, National Center for Radiation Research and Technology, Atomic Energy Authority, \\ Cairo, Egypt
}

ARTICLE INFO

Article history:

Received 12 November 2015

Accepted 22 November 2015

Keywords:

Resveratrol;

Sodium selenite;

Antioxidant;

Anticancer;

Anti-inflammatory;

Antiangiogenesis;

$\gamma$-irradiation;

Ehrlich ascites carcinoma.

\begin{abstract}
A B S T R A C T
Resveratrol (trans-3, 5, 4'-trihydroxystilbene) is a polyphenol non-flavonoid compound, particularly abundant in red grapes but it is also present in highly pigmented vegetables and fruits. It has been proven to be a potent antioxidant, anticancer, anti-inflammatory agent and recently it is proposed to have an antiangiogenic property. In this study, resveratrol $25 \mathrm{mg} / \mathrm{kg}$ body weight and sodium selenite $5 \mu \mathrm{g} / \mathrm{mice}$ was investigated in vitro as well as in vivo via systemic intraperitoneal injection (i.p.) in female mice with or without $\gamma$-irradiation exposure targeting the improvement of cancer therapeutic protocols. Tumor necrosis factor- $\alpha$ (TNF- $\alpha$ ) and matrix metalloproteinase 2 and 9 (MMP-2\&-9) are the angiogenic regulators, lactate dehydrogenase (LDH), as well as superoxide dismutase (SOD), catalase (CAT) and reduced glutathione (GSH) are the antioxidant markers and lipid peroxide (LPx) is an oxidative stress marker were estimated to monitor efficacy of resveratrol and sodium selenite in cancer treatment strategy. All parameters were determined as a time course on days 16 and 22 after tumor volume reached $1 \mathrm{~cm}^{3}$. The using of MTT assay on Ehrlich ascites carcinoma (EAC) cells in vitro showed that resveratrol and/or sodium selenite inhibit EAC cells proliferation. In vivo, administration of resveratrol and /or sodium selenite to mice bearing tumor and/or $\gamma$-irradiation reduced significantly the MMP- 2 and 9 activities TNF- $\alpha$ level and LDH activity while, increase in the activities of liver antioxidant enzymes SOD, CAT and GSH concentration. It could be postulated that the combination of resveratrol and sodium selenite may used as modulators of cancer therapy via inhibit cancer growth through controlling the reactive oxygen species and angiogenic process.
\end{abstract}

\section{Introduction}

Cancer is a disease caused by a heterogeneous collection of dysregulated cellular signaling processes involved in cell proliferation and homeostasis and caused by a combination of genetic mutations and/or internal or external oncogenic stimuli ${ }^{[1]}$. Cancer etiology is a multistep process and cancer cells acquire the following characteristics: uncontrolled growth in the absence of growth signals, resistance to antiproliferative signals, evasion from apoptosis, limitless replication, development of new blood vessels [angiogenesis], and invasion to surrounding tissue and metastasis to distal organs. Metastatic spread of cancer cells depends on an adequate supply of oxygen and nutrients and removal of waste products. Angiogenesis is regulated by both

* Corresponding author.

E-mail address: mohamed_elsotohi@sci.asu.edu.eg activator and inhibitor molecules ${ }^{[2]}$.

Angiogenesis is a fundamental process in reproduction and wound healing. Under these conditions, neovascularization is tightly regulated ${ }^{[3]}$; unregulated angiogenesis may result in different pathologies including cancer ${ }^{[4]}$. The construction of a vascular network requires different sequential steps including the release of proteases from "activated" endothelial cells with subsequent degradation of the basement membrane surrounding the existing vessel, migration of endothelial cells into the interstitial space, endothelial cell proliferation, and differentiation into mature blood vessels ${ }^{[5]}$. These processes are mediated by a wide range of angiogenic inducers, including growth factors, angiogenic enzymes, endothelial specific receptors, and adhesion molecules [5]. Many different proteins have been identified as angiogenic activators such as TNF- $\alpha$, 
MMP-2 and MMP-9. Levels of expression of angiogenic factors reflect the aggressiveness of tumor cells. The discovery of angiogenic inhibitors should help to reduce both morbidity and mortality from carcinomas [2]. Targeting inhibition of angiogenesis represents a potential approach in the treatment of solid tumors and such antiangiogenic strategies inhibiting the growth of endothelial cells may be more advantageous than targeting cancer cells ${ }^{[6]}$.

Polyphenols are considered as major nutrients for improving general health and providing cure for certain specific pathological conditions ${ }^{[7]}$. They act via different mechanisms to inhibit the angiogenesis process by utilizing various components of tumor angiogenesis signaling pathway, which starts from the tumor cells secreting angiogenesis factors and ending in the formation of blood capillaries by endothelial cells ${ }^{[8]}$.

Resveratrol [Res] is a polyphenol non-flavonoid compound, particularly abundant in red grapes [Vitis vinifera] and in highly pigmented vegetables and fruits ${ }^{[9]}$. It has been proven to be a potent antioxidant ${ }^{[10]}$, anticancer ${ }^{[11]}$. Functionally, it belongs to phytoalexins, also called the plant antibiotics ${ }^{[12]}$.

Selenium is an essential trace element existing in organic and inorganic chemical forms which have been shown to play an important role in maintenance of an optimal physiological state of mammalian cells. It has recognized a chemopreventive potential against various forms of environmental stress as well as against tumor development ${ }^{[13]}$.

The present study evaluated the influence of the angiogenic regulators modification on the tumor growth targeting the improvement of cancer therapeutic protocols with or without $\gamma$-irradiation. Thus, the action of resveratrol and/or sodium selenite was examined in vitro on Ehrlich ascites carcinoma cells and in vivo in mice bearing Ehrlich cells a model of solid carcinoma tumor and/or $\gamma$-Irradiated.

\section{Materials and Methods}

\section{Experimental animals}

All animal procedures and experimental protocols were approved by the Research Ethics Committee and were carried out in accordance with the guide for the care and use of laboratory animals. Swiss albino mice weighting 20 - $25 \mathrm{~g}$ were obtained from the Egyptian Organization for Biological Products and Vaccines (Vacsera, Egypt) and housed under controlled conditioning $25 \pm 1^{\circ} \mathrm{C}$ constant temperature, $55 \%$ relative humidity and $12 \mathrm{hrs}$ dark/light cycles. Food and water were allowed ad libitum during the study period.

\section{Tumor cell line}

Ehrlich ascites carcinoma (EAC) cell line was purchased from the Tumor Biology Department, National Cancer Institute, Cairo University. EAC is a murine spontaneous breast cancer that served as the original tumor from which an ascites variant was obtained. Intraperitoneal inoculation in female mice resulted in the production of ascites rich in tumor cells. The tumor cell line was maintained in our laboratory by serial i.p. passage in female Swiss albino mice at 7 or 10 days after passage. The EAC cells were prepared under aseptic conditions. EAC cells were tested for viability and contamination using Trypan blue dye exclusion technique ${ }^{[14]}$. EAC cells were suspended in normal saline so that each $0.2 \mathrm{ml}$ contains $2.5 \times 10^{6}$ EAC cells. Cells were counted under the microscope using Neubauer hemocytometer.

\section{Irradiation}

Irradiation was performed at the National Center for Radiation Research and Technology (NCRRT), Nasr city, Cairo, Egypt. The source of radiation was through Ceasium-137 $\left({ }^{137} \mathrm{Cs}\right)$ gamma cell-40 which ensured a homogenous dose distribution all over the irradiation tray. Mice were placed in a specially designed wellventilated acrylic container and whole body irradiated at dose level of 6.5 Gy. A line of Ehrlich Ascites Carcinoma (EAC) cells was irradiated also at dose level of $6.5 \mathrm{~Gy}$. The dose rate was $0.66 \mathrm{~Gy} / \mathrm{min}$ single shot dose during the experimental periods.

\section{In vitro study}

The viability test 3-[4, 5-dimethylthiazol-2-y1]-2, 5diphenyl tetrazolium bromide (MTT) Assay ${ }^{[15]}$ is a sensitive, quantitative and reliable colorimetric assay that measures viability, proliferation and activation of cells. The assay is based on the capacity of mitochondrial dehydrogenase enzymes in living cells to convert the yellow water-soluble substrate MTT into purple-blue formazan crystals determined spectro-photochemically and serves as estimation for the mitochondrial activity and hence the number of living cells in the sample ${ }^{[16]}$.

\section{In vivo study}

\section{Induction of solid tumors}

Solid tumors were produced by intramuscular inoculation in the right thigh of the lower limb of each mouse with $0.2 \mathrm{ml}$ of EAC cells, which contained $2.5 \mathrm{x}$ $10^{6}$ viable EAC cells. Mice with a palpable solid tumor mass $1 \mathrm{~cm}^{3}$ that developed within 14 days after inoculation were used in the study. Tumor volume was measured at different time intervals during the experimental period days $6,13,16$, and 22 using a vernier caliper and calculated ${ }^{[17]}$.

\section{Treatments}

Resveratrol (Res) was dissolved in dimethyl sulphoxide (DMSO) and phosphate buffer saline (PBS) DMSO: PBS (1:20) and given to mice by daily i.p. injection dose of $25 \mathrm{mg} / \mathrm{kg}$ body weight ${ }^{[18]}$ for 14 successive days. Sodium selenite (Sse) was dissolved in $0.9 \%$ saline and given to mice by i.p. injection of the maximal tolerated dose $5 \mu \mathrm{g} /$ mice $^{[19]}$, once every day for 14 successive days.

\section{Work design}

The animal groups were randomly categorized into 16 groups, 10 mice each, as follows:

\section{I. control groups}

Group (1) Control (C), mice received vehicle injection (DMSO in PBS). 
Group (2) Resveratrol (Res), mice i.p. injected with Res for 14 consecutive days.

Group (3) Sodium selenite (Sse), mice i.p. injected with Sse for 14 consecutive days.

Group (4) Res+ Sse, mice i.p. injected with a mixture of Res and Sse for 14 consecutive days.

\section{Irradiated groups}

Group (5) Irradiated (Irr), mice were whole body $\gamma$ irradiated with $6.5 \mathrm{~Gy}$, single dose.

Group (6) Res+Irr, mice i.p. injected with Res for 14 consecutive days and $\gamma$-irradiation $24 \mathrm{hrs}$. after the last Res injected dose.

Group (7) Sse+Irr, mice i.p. injected with Sse for 14 consecutive days and $\gamma$-irradiated with 6.5 Gy 24 hrs. after the last Sse injected dose.

Group (8) Res+Sse+Irr, mice (i.p.) injected with a mixture of Res and Sse for 14 consecutive days and $\gamma$ irradiated with $6.5 \mathrm{~Gy} 24 \mathrm{hrs}$. after the last injected dose.

\section{Ehrlich groups}

Group (9) Ehrlich (E), mice bearing solid Ehrlich tumor.

Group (10) E+Res, mice bearing were received 14 successive Res dose starting from the $15^{\text {th }}$ day after EAC inoculation.

Group (11) E+Sse, mice bearing solid Ehrlich tumor were received 14 successive Sse dose starting from the $15^{\text {th }}$ day after EAC inoculation.

Group (12) E+Res+Sse, mice bearing solid Ehrlich tumor were received 14 successive Res+Sse dose starting from the $15^{\text {th }}$ day after EAC inoculation.

\section{Ehrlich- Irradiated groups}

Group (13) E+Irr, mice bearing solid Ehrlich tumor and exposed to $\gamma$-irradiation $6.5 \mathrm{~Gy}$ on $29^{\text {th }}$ day after EAC inoculation.

Group (14) E+Res+Irr, mice bearing solid Ehrlich tumor i.p. injected with Res for 14 consecutive days and exposed to $\gamma$-irradiation 6.5 Gy $24 \mathrm{hrs}$. after the last injected dose.

Group (15) E+Sse+Irr, mice bearing solid Ehrlich tumor i.p. injected with Sse for 14 consecutive days and exposed to $\gamma$-irradiation 6.5 Gy $24 \mathrm{hrs}$. after the last injected dose.

Group (16) E+Res+Sse+Irr, mice bearing i.p. injected with Res+Sse for 14 consecutive days and exposed to $\gamma$ irradiation $6.5 \mathrm{~Gy} 24 \mathrm{hrs}$. after the last injected dose.

\section{Sample collections}

Animals were fasted for $16 \mathrm{hrs}$ before each sampling. Samples were collected on $16^{\text {th }}$ and $22^{\text {th }}$ days post the tumor volume reached $1 \mathrm{~cm}^{3}$. Animals were sacrificed and the blood was collected from heart puncher and left for coagulation and was centrifuged for collecting serum. MMPs, TNF- $\alpha$ and LDH were measured in serum of each group. The tissues of liver and solid tumor of experimental animals were dissected out and divided into two parts: one part was dissected, weighed and homogenized in physiological saline for SOD, CAT, GSH and TBARS detection. Another portion of liver tissues was kept in $10 \%$ formalin for histopathological studies.
Total protein concentration was assayed in serum by means of Biuret reaction according to ${ }^{[20]}$ and the presence and activity of specific MMP species MMP- 2 $\&-9$ were initially detected in the serum using substrate (gelatin) gel electrophoresis ${ }^{[21]}$. A buffer of $4 \%$ SDS, $0.15 \mathrm{~mol} / \mathrm{L}$ Tris $(\mathrm{pH}$ 6.8), $20 \%$ glycerol and $0.5 \%(\mathrm{w} / \mathrm{v})$ bromophenol blue was added to the serum sample. Volume serum samples mixed with buffer were directly added to $10 \%$ SDS-acrylamide gel containing $0.1 \%$ $(\mathrm{w} / \mathrm{v})$ gelatin (sigma) and separated by running on a mini gel apparatus at $15 \mathrm{~mA} / \mathrm{gel}$, and then gels were gently rocked in a $2.5 \%$ Triton X-100 solution for $30 \mathrm{~min}$ at room temperature. Gels were then incubated overnight at $37{ }^{\circ} \mathrm{C}$ in substrate buffer containing $50 \mathrm{mmol} / \mathrm{L}$ Tris$\mathrm{HCl}(\mathrm{pH} 8), 5 \mathrm{~m} \mathrm{~mol} / \mathrm{L} \mathrm{CaCl}_{2}$ and $0.02 \% \mathrm{NaN}_{3}$. Gel was subsequently stained for $30 \mathrm{~min}$ in $0.5 \%$ Coomassie Blue R-250 dissolved in a 1:3:6 solutions of acetic acid, isopropyl alcohol and water. The gel was scored for the presence/absence MMP activity by a blinded evaluator and photographed. MMP-2 and MMP-9 could be detected on the SDS gel as transparent bands.

\section{Biochemical assays}

\section{Tumor necrosis factor-alpha (TNF- $\alpha$ ) level}

The levels of TNF- $\alpha$ in serum were assayed by standard sandwich enzyme-linked immune-sorbent assay technique (ELISA) using ELISA kit (K0331186, KOMABIOTECH, Seoul, Korea) following the manufacturer's instructions based on the principle of a solid phase ELISA ${ }^{[22]}$.

\section{Lactate dehydrogenase (LDH) activity}

Serum LDH was detected according to the applied LDH kit test ${ }^{[23]}$, (Puruvate. Kinetic UV. DGKC. Liquid), where one international unit (IU) is the amount of enzyme that transforms $1 \mu \mathrm{mol}$ of substrate per minute, in standard condition is expressed in units per litre of sample U/L.

\section{Antioxidant and oxidative stress markers}

Liver and tumor superoxide dismutase (SOD) activitie was estimated by detection of superoxide anions using nitroblue tetrazoluim formazan color development according to ${ }^{[24]}$, where One unit $(50 \%$ inhibitory level of the enzyme) corresponds to $7.47 \mu \mathrm{g} / \mathrm{ml}$ of reaction mixture of SOD. Liver and tumor catalase (CAT) activity was assayed according to ${ }^{[25]}$. Liver and tumor reduced glutathione (GSH) concentration was assayed according to ${ }^{[26]}$. Liver and tumor lipid peroxide (LPx) content was determined by quantifying the thiobarbituric acid reactive substances (TBARs) according to ${ }^{[27]}$.

\section{Statistical Analysis}

Statistical analysis of results including the mean and standard error (SE) values were performed using Statistical Package for Social Science (SPSS) for windows, version 15. Chicago, SPSS Inc. Released 2006. All data are given as means \pm SE. Data were analyzed statistically using one-way analysis of variance (ANOVA) followed by Post Hoc LSD test. Differences were considered significant at $p<0.05$. 


\section{Results}

\section{In Vitro study}

The MTT test shows significant alteration in the EAC cells viability when incubated with different concentrations of resveratrol and/or sodium selenite (Table 1). Res and Sse inhibit cells growth in a dose dependent manner. The maximal inhibitory concentration of Res and Sse were aproximately
$100 \mu \mathrm{M}$ and $5 \mu \mathrm{g} / \mathrm{ml}$, respectively, after $24 \mathrm{hrs}$ of incubation. When cells were incubated with $80 \mu \mathrm{M}$ Res and $5 \mu \mathrm{g}$ Sse, synergistic anti-proliferative effect was observed. The Sse and Res combination induced 91\%. Figure (1) showed inhibition of cell growth. The radiation exposure of EAC cells treated with $80 \mu \mathrm{M}$ Res and $5 \mu \mathrm{g}$ Sse showed dramatic cell growth inhibition $96 \%$.

Table 1: Effect of different concentrations of resveratrol and resveratrol accompanied with $5 \mu \mathrm{g} / \mathrm{ml}$ sodium selenite on the viability of EAC or irradiated EAC cells, after 24 hrs incubation, using the MTT assay.

\begin{tabular}{|c|c|c|c|}
\hline \multicolumn{2}{|c|}{ EAC cells } & \multicolumn{2}{c|}{ Irradiated EAC cells } \\
\hline Concentrations & \% of cell inhibition & Concentrations & \% of cell inhibition \\
\hline \multicolumn{2}{|c|}{ Resveratrol } & \multicolumn{2}{|c|}{ Resveratrol } \\
\hline 0 & $0 \%$ & 0 & $0 \%$ \\
\hline $30 \mu \mathrm{M}$ & $12 \%$ & $30 \mu \mathrm{M}$ & $23 \%$ \\
\hline $50 \mu \mathrm{M}$ & $25 \%$ & $50 \mu \mathrm{M}$ & $35 \%$ \\
\hline $60 \mu \mathrm{M}$ & $34 \%$ & $60 \mu \mathrm{M}$ & $48 \%$ \\
\hline $80 \mu \mathrm{M}$ & $45 \%$ & $80 \mu \mathrm{M}$ & $54 \%$ \\
\hline $100 \mu \mathrm{M}$ & $51 \%$ & $100 \mu \mathrm{M}$ & $69 \%$ \\
\hline Resveratrol with $\mathbf{5} \boldsymbol{\mu} \mathbf{g} / \mathbf{m l}$ sodium selenite & Resveratrol with $\mathbf{5} \boldsymbol{\mu g}$ /ml sodium selenite \\
\hline 0 & $0 \%$ & 0 & $0 \%$ \\
\hline $30 \mu \mathrm{M}$ & $70 \%$ & $30 \mu \mathrm{M}$ & $82 \%$ \\
\hline $50 \mu \mathrm{M}$ & $79 \%$ & $50 \mu \mathrm{M}$ & $85 \%$ \\
\hline $60 \mu \mathrm{M}$ & $83 \%$ & $60 \mu \mathrm{M}$ & $92 \%$ \\
\hline $80 \mu \mathrm{M}$ & $91 \%$ & $80 \mu \mathrm{M}$ & $96 \%$ \\
\hline $100 \mu \mathrm{M}$ & $94 \%$ & $100 \mu \mathrm{M}$ & $98 \%$ \\
\hline
\end{tabular}

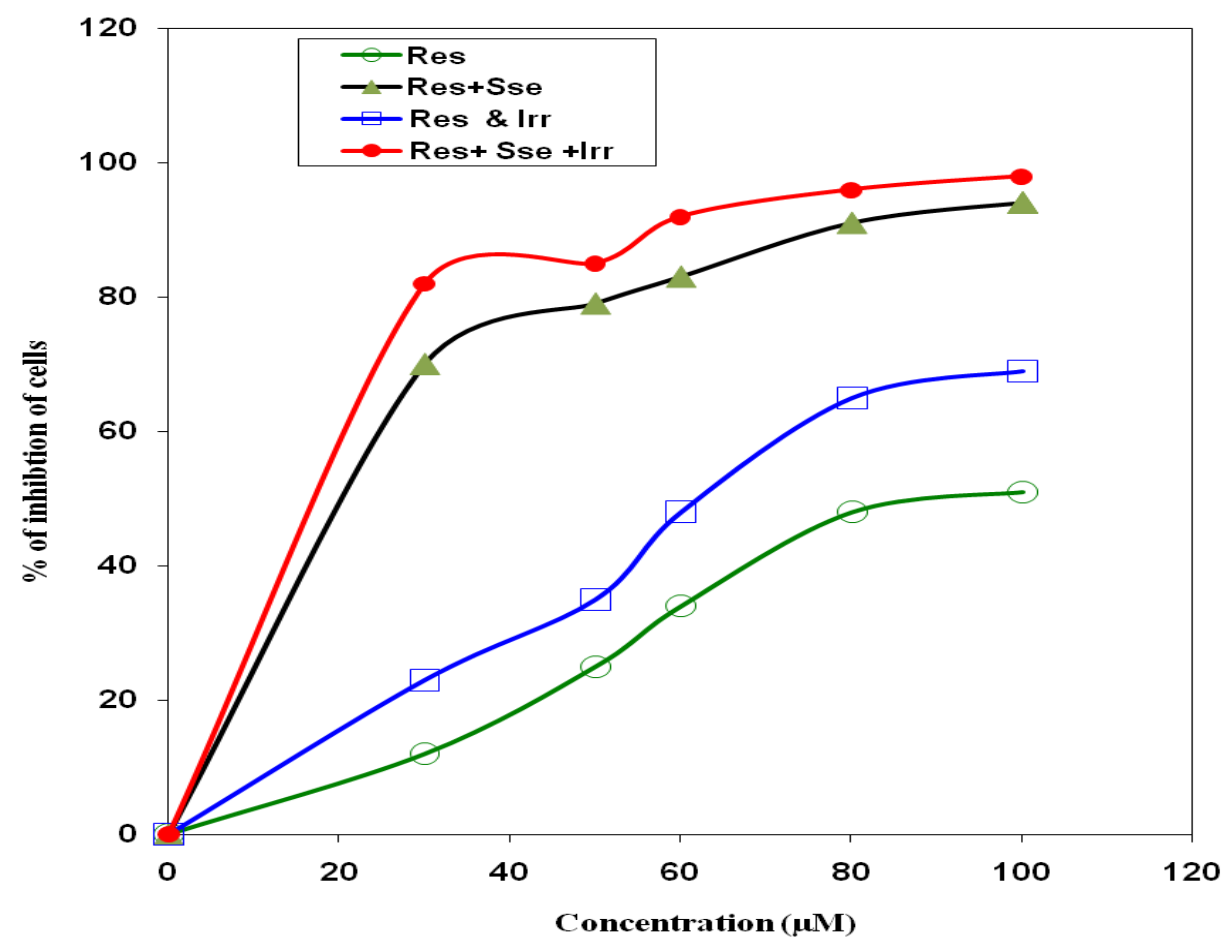

Fig. 1: Cell viability at different resveratrol doses $(\mu \mathrm{M})$ and resveratrol accompanied with $5 \mu \mathrm{g} / \mathrm{ml}$ sodium selenite. 


\section{In Vivo study}

\section{Tumor volume $\left(\mathrm{mm}^{3}\right)$}

Data obtained in Table (2) revealed a consecutive treatment of the animals with Res, Sse or their combination for 14 days starting after the tumor volume reached $1 \mathrm{~cm}^{3}$ at 14 days after tumor inoculation, caused a marked suppression of tumor growth at days 6 , 13,16 and 22 from the day of tumor volume reaching 1 $\mathrm{cm}^{3}$. Whole body $\gamma$-irradiation of mice bearing a tumor and treated with Res and/or Sse for 14 days showed a marked reduction in tumor volume at 16 days, and a further significant suppression at 22 days, compared to that in the non treated mice bearing Ehrlich. The E +Res + Sse +Irr mice reveal the most reduced tumor volume as compared with other groups.

\section{Serum MMP-2 and MMP9 activities}

Table (3) and Fig 2 (A\&B) demonstrate that the activity of serum MMP-2 and MMP-9 in Irr, E or E+Irr mice group was significantly increased, compared to control mice group, also the activity of serum MMP-2\& -9 in E+Irr mice group was significantly increased, compared to Ehrlich mice group on $1^{\text {st }}$ day and $1^{\text {st }}$ week post irradiation. In contrast, a significant reduction in the serum activity of MMP-2 and MMP-9 in EAC bearing mice treated with Res, Sse or Res + Sse before exposure to $\gamma$-irradiation, compared to Ehrlich mice group. The results revealed that Res + Sse combination showed more pronounced decrease in serum MMP-2\&MMP-9 activities than Res or Sse alone.

\section{Serum TNF- $\alpha$ level}

Table (4) revealed that serum TNF- $\alpha$ of Irr, E or E+Irr mice group showed significant increase, compared to control group on the $1^{\text {st }}$ day and $1^{\text {st }}$ week post irradiation, also E+Irr showed significant increase in serum TNF- $\alpha$, compared to Ehrlich group. In contrast $\gamma$-irradiated mice group (Irr) showed significant decrease in serum TNF- $\alpha$, compared to Ehrlich group (E).

Treatment of mice bearing tumor (E) mice group with Res, Sse or Res+ Sse had a significant decrease in TNF- $\alpha$ concentration, compared to Ehrlich group on the $1^{\text {st }}$ day and $1^{\text {st }}$ week post irradiation. Furthermore, E+Irr mice group treated with Res, Sse or Res+Sse showed significant decrease in TNF- $\alpha$ concentration, compared to Ehrlich group on the $1^{\text {st }}$ day and $1^{\text {st }}$ week post irradiation. The result revealed that Res + Sse induced more pronounced decrease in TNF- $\alpha$ concentration than Res or Sse alone.

Table 2: Tumor volume measurements $\left(\mathrm{mm}^{3}\right)$ in the different animal groups.

\begin{tabular}{|c|c|c|c|c|c|c|c|c|}
\hline \multirow{3}{*}{$\begin{array}{l}\text { Experimental } \\
\text { Days of Tumor } \\
\text { Measurement } \\
\left(\mathrm{mm}^{3}\right)\end{array}$} & \multicolumn{4}{|c|}{ Ehrlich animal groups } & \multicolumn{4}{|c|}{ Ehrlich-irradiated animal groups } \\
\hline & $\mathbf{E}$ & E + Res & $\mathbf{E}+$ Sse & $\begin{array}{c}\text { E+ Res + } \\
\text { Sse } \\
\end{array}$ & E+Irr & $\begin{array}{c}\text { E+ Res + } \\
\text { Irr } \\
\end{array}$ & $\begin{array}{c}\mathrm{E}+\mathrm{Sse}+ \\
\text { Irr } \\
\end{array}$ & $\begin{array}{c}\text { E + Res+ } \\
\text { Sse+ Irr }\end{array}$ \\
\hline & G9 & G10 & G11 & G12 & G13 & G14 & G15 & G16 \\
\hline 6 day & $916 \pm 53$ & $490^{\mathrm{b}} \pm 25$ & $365^{\mathrm{b}} \pm 25$ & $278^{\mathrm{b}} \pm 26$ & & & & \\
\hline 13 day & $1592 \pm 45$ & $874^{\mathrm{b}} \pm 59$ & $657^{\mathrm{b}} \pm 43$ & $558^{\mathrm{b}} \pm 39$ & & & & \\
\hline 16 day & $1900^{c} \pm 46$ & $1545^{\mathrm{bc}} \pm 47$ & $1285^{\mathrm{bc}} \pm 10$ & $1136^{\mathrm{bc}} \pm 54$ & $901^{\mathrm{b}} \pm 19$ & $823^{b c} \pm 33$ & $737^{\mathrm{bc}} \pm 25$ & $674^{\mathrm{bc}} \pm 17$ \\
\hline 22 day & $2066^{\mathrm{c}} \pm 54$ & $1869^{\mathrm{bc}} \pm 55$ & $1723^{\mathrm{bc}} \pm 24$ & $1512^{\mathrm{bc}} \pm 43$ & $1397^{\mathrm{b}} \pm 52$ & $1219^{\mathrm{bc}} \pm 39$ & $1112^{\mathrm{bc}} \pm 51$ & $939^{\mathrm{bc}} \pm 46$ \\
\hline
\end{tabular}

Irr: Irradiation; E: Ehrlich; Res: resveratrol; Sse: sodium selenite. Each value represents Mean \pm SE of 6 observations, Values with dissimilar super script letters are considered significantly different at $p<0.05$. b: significant against Ehrlich group (G9). c: significant against E+Irr.
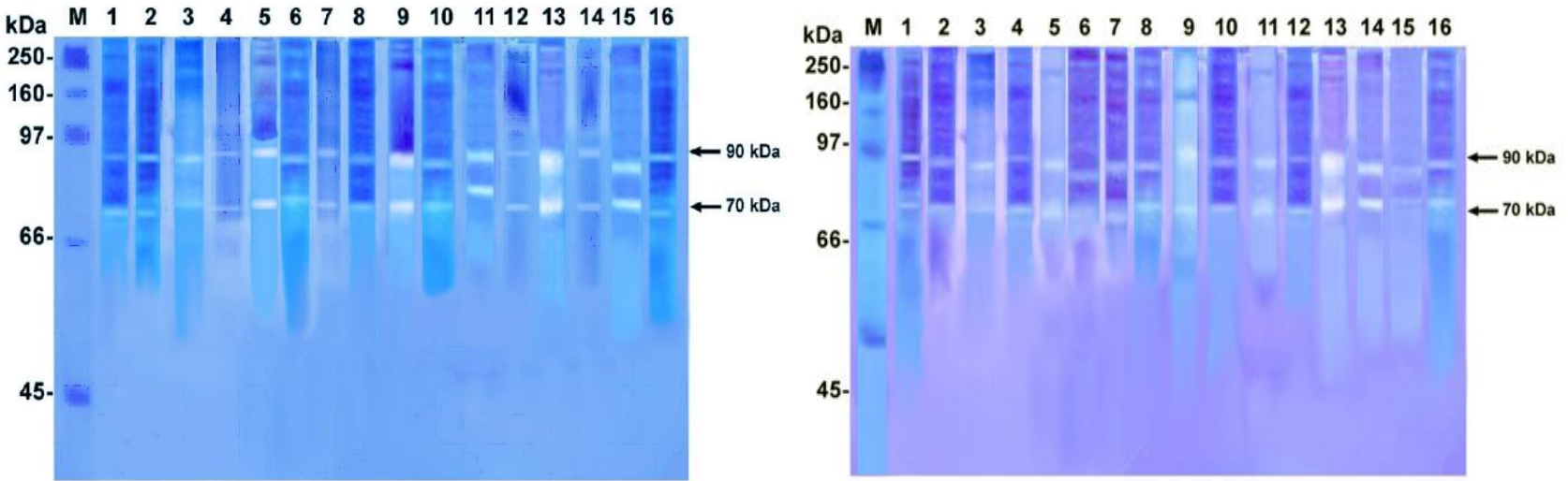

Fig. 2 (A\&B): Gelatin zymography of serum MMP-(2 and 9) activities (70 \& $90 \mathrm{kDa})$ in all studied groups on $1^{\text {st }}$ day and $1^{\text {st }}$ week post irradiation, respectively. Lane (M): Protein marker; Lanes (1-16) are groups from control to E, Res, Sse, Irr as ordered in Table (4). 
Table 3: Serum MMP-2\&-9 activities in the different animal groups on $1^{\text {st }}$ day and $1^{\text {st }}$ week post irradiation.

\begin{tabular}{|c|c|c|c|c|c|c|c|c|c|c|c|c|c|c|c|c|}
\hline \multirow{3}{*}{ parameter } & \multicolumn{4}{|c|}{ Control groups } & \multicolumn{4}{|c|}{ Irradiated groups } & \multicolumn{4}{|c|}{ Ehrlich groups } & \multicolumn{4}{|c|}{ Ehrlich- Irradiated groups } \\
\hline & C & Res & Sse & $\begin{array}{l}\text { Res+ } \\
\text { Sse }\end{array}$ & Irr & $\begin{array}{c}\text { Res+ } \\
\text { Irr }\end{array}$ & $\begin{array}{l}\text { Sse+ } \\
\text { Irr }\end{array}$ & $\begin{array}{c}\text { Res+ } \\
\text { Sse+ } \\
\text { Irr }\end{array}$ & $\mathbf{E}$ & $\begin{array}{l}\text { E+ } \\
\text { Res }\end{array}$ & $\begin{array}{l}\text { E+ } \\
\text { Sse }\end{array}$ & $\begin{array}{c}\text { E+ } \\
\text { Res+ } \\
\text { Sse }\end{array}$ & $\begin{array}{l}\text { E+ } \\
\text { Irr }\end{array}$ & $\begin{array}{c}\text { E+ } \\
\text { Res+ } \\
\text { Irr }\end{array}$ & $\begin{array}{c}\text { E+ } \\
\text { Sse+ } \\
\text { Irr }\end{array}$ & $\begin{array}{c}\text { E+ } \\
\text { Res+ } \\
\text { Sse+ } \\
\text { Irr } \\
\end{array}$ \\
\hline & G1 & G2 & G3 & G4 & G5 & G6 & G7 & G8 & G9 & G10 & G11 & G12 & G13 & G14 & G15 & G16 \\
\hline MMP-2 & \multicolumn{16}{|c|}{ (U/mg) } \\
\hline $\begin{array}{l}1^{\text {st }} \text { day post } \\
\text { irradiation }\end{array}$ & $\begin{array}{c}79.9^{\mathrm{b}} \\
\pm \\
5.2\end{array}$ & $\begin{array}{c}83^{\mathrm{b}} \\
\pm \\
6.2\end{array}$ & $\begin{array}{c}81^{\mathrm{b}} \\
\pm \\
2.2\end{array}$ & $\begin{array}{c}81.8^{\mathrm{b}} \\
\pm \\
7.5\end{array}$ & $\begin{array}{c}231^{\mathrm{ab}} \\
\pm \\
15.4\end{array}$ & $\begin{array}{c}165^{\mathrm{ab}} \\
\pm \\
4.8\end{array}$ & $\begin{array}{c}199^{\mathrm{ab}} \\
\pm \\
5.5\end{array}$ & $\begin{array}{c}149^{\mathrm{ab}} \\
\pm \\
2.3\end{array}$ & $\begin{array}{c}179^{\mathrm{a}} \\
\pm \\
6.8\end{array}$ & $\begin{array}{c}123^{\mathrm{ab}} \\
\pm \\
3\end{array}$ & $\begin{array}{c}148^{\mathrm{ab}} \\
\pm \\
2.2\end{array}$ & $\begin{array}{c}110^{\mathrm{ab}} \\
\pm \\
3.8\end{array}$ & $\begin{array}{c}284^{\mathrm{ab}} \\
\pm \\
14.9\end{array}$ & $\begin{array}{c}241^{\mathrm{ab}} \\
\pm \\
4.9\end{array}$ & $\begin{array}{c}255^{\mathrm{ab}} \\
\pm \\
2.5\end{array}$ & $\begin{array}{c}190^{\mathrm{ab}} \\
\pm \\
3.2\end{array}$ \\
\hline$\%$ Change & 0 & 4 & 1 & 2 & 189 & 106 & 149 & 87 & 124 & 53 & 86 & 37 & 255 & 195 & 219 & 138 \\
\hline $\begin{array}{c}1^{\text {st }} \text { week } \\
\text { post } \\
\text { irradiation }\end{array}$ & $\begin{array}{c}81.7^{\mathrm{b}} \\
\pm \\
1.7\end{array}$ & $\begin{array}{c}78.5^{\mathrm{b}} \\
\pm \\
4.4\end{array}$ & $\begin{array}{c}76.8^{\mathrm{b}} \\
\pm \\
3.5\end{array}$ & $\begin{array}{c}84.9^{\mathrm{b}} \\
\pm \\
3.6\end{array}$ & \begin{tabular}{c|}
$359^{\mathrm{ab}}$ \\
\pm \\
7.9
\end{tabular} & $\begin{array}{c}243^{\mathrm{ab}} \\
\pm \\
7.14\end{array}$ & $\begin{array}{c}274^{\mathrm{ab}} \\
\pm \\
4.9\end{array}$ & $\begin{array}{c}231^{\mathrm{ab}} \\
\pm \\
4.6\end{array}$ & $\begin{array}{c}285^{\text {ab }} \\
\pm \\
5\end{array}$ & $\begin{array}{c}176^{\mathrm{a}} \\
\pm \\
4.3\end{array}$ & $\begin{array}{c}195^{\text {ab }} \\
\pm \\
6.1\end{array}$ & $\begin{array}{c}154^{\mathrm{ab}} \\
\pm \\
2.5\end{array}$ & $\begin{array}{c}337^{\text {ab }} \\
\pm \\
9.8\end{array}$ & $\begin{array}{c}282^{\text {ab }} \\
\pm \\
3.8\end{array}$ & \begin{tabular}{|c|}
$288^{\mathrm{ab}}$ \\
\pm \\
5.2
\end{tabular} & $\begin{array}{c}234^{\mathrm{ab}} \\
\pm \\
9.3\end{array}$ \\
\hline$\%$ Change & 0 & -4 & -6 & 4 & 340 & 198 & 235 & 182 & 248 & 116 & 138 & 39 & 312 & 244 & 252 & 188 \\
\hline LSD & \multicolumn{16}{|c|}{29.9} \\
\hline & G1 & G2 & G3 & G4 & G5 & G6 & G7 & G8 & G9 & G10 & G11 & G12 & G13 & G14 & G15 & G16 \\
\hline MMP-9 & \multicolumn{16}{|c|}{ (U/mg) } \\
\hline $\begin{array}{l}1^{\text {st }} \text { day post } \\
\text { irradiation }\end{array}$ & $\begin{array}{c}176^{\mathrm{b}} \\
\pm \\
2.1\end{array}$ & $\begin{array}{c}177^{\mathrm{b}} \\
\pm \\
1.7\end{array}$ & $\begin{array}{c}174^{\mathrm{b}} \\
\pm \\
2.3\end{array}$ & $\begin{array}{c}182^{\mathrm{b}} \\
\pm \\
4.1\end{array}$ & \begin{tabular}{c|}
$495^{\mathrm{ab}}$ \\
\pm \\
2.2
\end{tabular} & $\begin{array}{c}302^{\mathrm{a}} \\
\pm \\
1.8\end{array}$ & $\begin{array}{c}325^{\text {ab }} \\
\pm \\
2.8\end{array}$ & $\begin{array}{c}244^{\mathrm{ab}} \\
\pm \\
7.5\end{array}$ & $\begin{array}{c}312^{\mathrm{a}} \\
\pm \\
4.9\end{array}$ & $\begin{array}{c}227^{\mathrm{ab}} \\
\pm \\
9.1\end{array}$ & $\begin{array}{c}266^{\mathrm{ab}} \\
\pm \\
6.9\end{array}$ & $\begin{array}{c}206^{\text {ab }} \\
\pm \\
2.6\end{array}$ & $\begin{array}{c}369^{\mathrm{ab}} \\
\pm \\
4.5\end{array}$ & $\begin{array}{c}248^{\mathrm{ab}} \\
\pm \\
4.8\end{array}$ & \begin{tabular}{c|}
$306^{\mathrm{a}}$ \\
\pm \\
3 \\
\end{tabular} & $\begin{array}{c}240^{\mathrm{ab}} \\
\pm \\
5.2\end{array}$ \\
\hline \% Change & 0 & 1 & -1 & 3 & 181 & 72 & 85 & 38 & 78 & 29 & 51 & 17 & 110 & 41 & 74 & 36 \\
\hline $\begin{array}{c}1^{\text {st }} \text { week } \\
\text { post } \\
\text { irradiation }\end{array}$ & $\begin{array}{c}177^{\mathrm{b}} \\
\pm \\
1.5\end{array}$ & $\begin{array}{c}175^{\mathrm{b}} \\
\pm \\
2.6\end{array}$ & $\begin{array}{c}182^{\mathrm{b}} \\
\pm \\
2.7\end{array}$ & $\begin{array}{c}189^{\mathrm{ab}} \\
\pm \\
2\end{array}$ & \begin{tabular}{c|}
$602^{\mathrm{ab}}$ \\
\pm \\
5.9
\end{tabular} & $\begin{array}{c}348^{\mathrm{ab}} \\
\pm \\
5.3\end{array}$ & $\begin{array}{c}396^{\mathrm{ab}} \\
\pm \\
7.1\end{array}$ & $\begin{array}{c}303^{\mathrm{a}} \\
\pm \\
7.1\end{array}$ & $\begin{array}{c}323^{\mathrm{a}} \\
\pm \\
3.7\end{array}$ & $\begin{array}{c}273^{\text {ab }} \\
\pm \\
2\end{array}$ & $\begin{array}{c}288^{\mathrm{ab}} \\
\pm \\
1.7\end{array}$ & $\begin{array}{c}242^{\mathrm{ab}} \\
\pm \\
1.9\end{array}$ & $\begin{array}{c}537^{\mathrm{ab}} \\
\pm \\
17.3\end{array}$ & $\begin{array}{c}316^{\mathrm{a}} \\
\pm \\
11.9\end{array}$ & \begin{tabular}{c|}
$345^{\mathrm{ab}}$ \\
\pm \\
5.6
\end{tabular} & $\begin{array}{c}286^{\mathrm{ab}} \\
\pm \\
3.0\end{array}$ \\
\hline$\%$ Change & 0 & -1 & 3 & 7 & 241 & 97 & 125 & 72 & 83 & 55 & 63 & 38 & 204 & 79 & 96 & 62 \\
\hline LSD & \multicolumn{16}{|c|}{12.6} \\
\hline
\end{tabular}

C: Control; Irr: Irradiation; E: Ehrlich; Res: Resveratrol; Sse: Sodium Selenite; LSD: Least significant difference. Each value represents Mean \pm SE of 6 observations, \%: Percent change from the values of control mice. Values with dissimilar super script letters are considered significantly different at $p<0.05$. a: significant against normal Control group (G1). b: significant against Ehrlich group (G9).

\section{Serum LDH activity}

Results presented in Table (4) revealed significant increase in LDH activity in serum of Irr, E or E+ Irr mice group, compared to control mice group, also serum LDH activity in E+Irr mice group was significantly increased, compared to Ehrlich mice group on $1^{\text {st }}$ day and $1^{\text {st }}$ week post irradiation. On the other hand, treatment of mice bearing tumor with Res or Res + Sse before exposure to $\gamma$-irradiation had a significant decrease in serum LDH activity, compared to Ehrlich bearing mice on $1^{\text {st }}$ day and $1^{\text {st }}$ week post irradiation. Furthermore, combined treatment with Res \& Sse to E+ Irr mice group showed significant reduction in serum LDH activity, compared to Ehrlich bearing mice on $1^{\text {st }}$ day and $1^{\text {st }}$ week post irradiation.The results revealed that Res + Sse combination showed more reduction in serum LDH activity than resveratrol or sodium selenite alone.

\section{Antioxidant and oxidative stress markers Liver tissue antioxidants}

Table (5) revealed significant decrease in the liver of Irr, E or E + Irr mice groups for antioxidant enzymes (SOD and CAT) activities and GSH concentration, resp- ectively, on $1^{\text {st }}$ day post and $1^{\text {st }}$ week post irradiation, compared to control mice group, also the liver of E+Irr mice group revealed significant decrease in CAT activity and GSH concentration, compared to Ehrlich group on $1^{\text {st }}$ day and $1^{\text {st }}$ week post irradiation. On the other hand, treatment of mice bearing tumor with Res, Sse or Res + Sse before and after exposure to $\gamma$-irradiation revealed significant increase in liver SOD activity, compared to Ehrlich bearing mice on $1^{\text {st }}$ day post and $1^{\text {st }}$ week post irradiation, while treatment of mice bearing tumor with Res, Sse or Res + Sse revealed significant increase in liver CAT activity, compared to Ehrlich bearing mice on $1^{\text {st }}$ day post irradiation and only Res + Sse on $1^{\text {st }}$ week post irradiation. Furthermore, liver CAT activity showed significant increase in E+ Irr treated groups with Res + Sse, compared to Ehrlich bearing mice on $1^{\text {st }}$ day post irradiation.

Treatment of mice bearing tumor with Res, Sse or Res + Sse revealed significant increase in liver GSH concentration, compared to Ehrlich bearing mice on $1^{\text {st }}$ day and $1^{\text {st }}$ week post irradiation, while treatment of E+ Irr treated groups with Res or Res + Sse revealed significant increase in liver GSH content, compared to 
Ehrlich bearing mice. The results revealed that Res + Sse combination showed higher increase in liver antioxidant markers than Res or Sse alone.

\section{Tumor tissue antioxidant enzyme}

Data represented in Table (6) revealed that the activities of tumor antioxidant enzymes (SOD and CAT) and tumor GSH concentration were significantly decreased in $\mathrm{E}+\mathrm{Irr}$ mice group, compared to Ehrlich bearing mice on $1^{\text {st }}$ day and $1^{\text {st }}$ week post irradiation in tumor SOD and CAT activities and on $1^{\text {st }}$ week post irradiation in tumor GSH content. Whole body $\gamma$-irradiation to mice bearing tumor treated with Res, Sse or Res + Sse had a significant decrease in tumor antioxidant markers on $1^{\text {st }}$ day and $1^{\text {st }}$ week post irradiation, compared to Ehrlich group, this decline was more evident $1^{\text {st }}$ week post irradiation.

Administration of Res, Sse or Res + Sse to EAC bearing mice before $\gamma$ - irradiation exposure (E) mice groups had a significant decrease in tumor CAT activity and GSH concentration on $1^{\text {st }}$ day and $1^{\text {st }}$ week post irradiation, compared to Ehrlich group, while Treatment of E mice groups with a mixture of Res and Sse had a significant decrease in tumor SOD activity on $1^{\text {st }}$ day and $1^{\text {st }}$ week post irradiation, compared to Ehrlich group. The results revealed that Res + Sse showed a significant decrease in tumor antioxidant markers than Res or Sse alone.

\section{Liver TBARS level}

Results presented at Table (5) revealed significant increase of TBARS concentration in liver of Irr, E or E+Irr mice group, compared to control mice group, also liver TBARS concentration of E+Irr mice group was significantly increased, compared to Ehrlich mice group on $1^{\text {st }}$ day and $1^{\text {st }}$ week post irradiation. In contrast, treatment of EAC bearing mice with Res, Sse or Res + Sse before exposure to $\gamma$-irradiation had a significant decrease in liver TBARS concentration, compared to Ehrlich bearing mice group on $1^{\text {st }}$ day and $1^{\text {st }}$ week post irradiation. Furthermore, liver TBARS concentration was significantly decreased in E+Irr mice group treated with Res on the $1^{\text {st }}$ week post irradiation, as well as Res or Res + Sse on the $1^{\text {st }}$ day post irradiation, compared to Ehrlich mice group. The results revealed that Res+ Sse exert more obvious decrease in liver TBARS concentration than Res or Sse alone.

Table 4: Serum TNF- $\alpha$ level and LDH activity in the different animal groups on $1^{\text {st }}$ day and $1^{\text {st }}$ week post irradiation.

\begin{tabular}{|c|c|c|c|c|c|c|c|c|c|c|c|c|c|c|c|c|}
\hline \multirow{3}{*}{ parameter } & \multicolumn{4}{|c|}{ Control groups } & \multicolumn{4}{|c|}{ Irradiated groups } & \multicolumn{4}{|c|}{ Ehrlich groups } & \multicolumn{4}{|c|}{ Ehrlich- Irradiated groups } \\
\hline & $\mathbf{C}$ & Res & Sse & $\begin{array}{l}\text { Res+ } \\
\text { Sse }\end{array}$ & Irr & $\begin{array}{c}\text { Res+ } \\
\text { Irr }\end{array}$ & $\begin{array}{c}\text { Sse+ } \\
\text { Irr }\end{array}$ & $\begin{array}{l}\text { Res+ } \\
\text { Sse+ } \\
\text { Irr }\end{array}$ & $\mathbf{E}$ & $\begin{array}{l}\text { E+ } \\
\text { Res }\end{array}$ & $\begin{array}{l}\text { E+ } \\
\text { Sse }\end{array}$ & $\begin{array}{c}\text { E+ } \\
\text { Res+ } \\
\text { Sse }\end{array}$ & $\begin{array}{l}\text { E+ } \\
\text { Irr }\end{array}$ & $\begin{array}{c}\text { E+ } \\
\text { Res+ } \\
\text { Irr }\end{array}$ & $\begin{array}{c}\text { E+ } \\
\text { Sse+ } \\
\text { Irr }\end{array}$ & $\begin{array}{c}\text { E+ } \\
\text { Res+ } \\
\text { Sse+ } \\
\text { Irr } \\
\end{array}$ \\
\hline & G1 & G2 & G3 & G4 & G5 & G6 & G7 & G8 & G9 & G10 & G11 & G12 & G13 & G14 & G15 & G16 \\
\hline TNF- $\alpha$ & \multicolumn{16}{|c|}{$(\mathrm{pg} / \mathrm{ml})$} \\
\hline $\begin{array}{l}1^{\text {st }} \text { day post } \\
\text { irradiation }\end{array}$ & $\begin{array}{c}88.3^{\mathrm{b}} \\
\pm \\
5.9\end{array}$ & $\begin{array}{c}93^{\mathrm{b}} \\
\pm \\
3.39\end{array}$ & $\begin{array}{c}97^{\mathrm{b}} \\
\pm \\
3.1\end{array}$ & $\begin{array}{c}92^{\mathrm{b}} \\
\pm \\
1.4\end{array}$ & $\begin{array}{c}217^{\mathrm{ab}} \\
\pm \\
9.9\end{array}$ & $\begin{array}{c}175^{\text {ab }} \\
\pm \\
3.7\end{array}$ & $\begin{array}{c}185^{\mathrm{ab}} \\
\pm \\
8.8\end{array}$ & $\begin{array}{c}137^{\mathrm{ab}} \\
\pm \\
7.5\end{array}$ & $\begin{array}{c}288^{\mathrm{a}} \\
\pm \\
8.8\end{array}$ & $\begin{array}{c}190^{\mathrm{ab}} \\
\pm \\
5.3\end{array}$ & $\begin{array}{c}197^{\mathrm{ab}} \\
\pm \\
9.3\end{array}$ & $\begin{array}{c}144^{\mathrm{ab}} \\
\pm \\
2\end{array}$ & $\begin{array}{c}334^{\mathrm{ab}} \\
\pm \\
16.3\end{array}$ & $\begin{array}{c}209^{\mathrm{ab}} \\
\pm \\
5.3\end{array}$ & $\begin{array}{c}214^{\mathrm{ab}} \\
\pm \\
7.5\end{array}$ & $\begin{array}{c}187^{\mathrm{ab}} \\
\pm \\
5.4\end{array}$ \\
\hline$\%$ Change & 0 & 6 & 10 & 4 & 146 & 99 & 110 & 55 & 227 & 116 & 123 & 63 & 280 & 137 & 143 & 112 \\
\hline $\begin{array}{c}1^{\text {st }} \text { week } \\
\text { post } \\
\text { irradiation }\end{array}$ & $\begin{array}{c}87^{\mathrm{b}} \\
\pm \\
2.4\end{array}$ & $\begin{array}{c}96^{\mathrm{ab}} \\
\pm \\
1.8\end{array}$ & $\begin{array}{c}98^{\mathrm{ab}} \\
\pm \\
3.1\end{array}$ & $\begin{array}{c}94^{\mathrm{ab}} \\
\pm \\
3\end{array}$ & $\begin{array}{c}230^{\mathrm{ab}} \\
\pm \\
4.7\end{array}$ & $\begin{array}{c}191^{\mathrm{ab}} \\
\pm \\
3.2\end{array}$ & $\begin{array}{c}197^{\mathrm{ab}} \\
\pm \\
2.7\end{array}$ & $\begin{array}{c}149^{\mathrm{ab}} \\
\pm \\
8.4\end{array}$ & $\begin{array}{c}319^{\mathrm{ab}} \\
\pm \\
13\end{array}$ & $\begin{array}{c}211^{\mathrm{ab}} \\
\pm \\
3.1\end{array}$ & $\begin{array}{c}217^{\mathrm{ab}} \\
\pm \\
9.8\end{array}$ & $\begin{array}{c}180^{\mathrm{ab}} \\
\pm \\
5.4\end{array}$ & $\begin{array}{c}365^{\mathrm{ab}} \\
\pm \\
13.3\end{array}$ & $\begin{array}{c}247^{\mathrm{ab}} \\
\pm \\
6.1\end{array}$ & $\begin{array}{c}259^{\mathrm{ab}} \\
\pm \\
12.8\end{array}$ & $\begin{array}{c}231^{\mathrm{ab}} \\
\pm \\
6.1\end{array}$ \\
\hline \% Change & 0 & -2 & 13 & 8 & 164 & 118 & 126 & 71 & 265 & 142 & 149 & 106 & 319 & 183 & 197 & 165 \\
\hline LSD & \multicolumn{16}{|c|}{48} \\
\hline & G1 & G2 & G3 & G4 & G5 & G6 & G7 & G8 & G9 & G10 & G11 & G12 & G13 & G14 & G15 & G16 \\
\hline LDH & \multicolumn{16}{|c|}{$(\mu \mathrm{mol} / \mathrm{L} / \mathrm{min})$} \\
\hline $\begin{array}{l}1^{\text {st }} \text { day post } \\
\text { irradiation }\end{array}$ & $\begin{array}{c}37.4^{\mathrm{b}} \\
\pm \\
0.90\end{array}$ & $\begin{array}{c}34.3^{\mathrm{b}} \\
\pm \\
0.20\end{array}$ & $\begin{array}{c}33.7^{\mathrm{b}} \\
\pm \\
1.65\end{array}$ & $\begin{array}{c}38.3^{\mathrm{b}} \\
\pm \\
0.23\end{array}$ & $\begin{array}{c}103^{\mathrm{a}} \\
\pm \\
7.1\end{array}$ & $\begin{array}{c}58.6^{\mathrm{b}} \\
\pm \\
5.3\end{array}$ & $\begin{array}{c}62.5^{\mathrm{b}} \\
\pm \\
3.18\end{array}$ & $\begin{array}{c}40.1^{\mathrm{b}} \\
\pm \\
0.35\end{array}$ & $\begin{array}{c}140^{\mathrm{a}} \\
\pm \\
6.3\end{array}$ & $\begin{array}{c}77.7^{\mathrm{b}} \\
\pm \\
3.29\end{array}$ & $\begin{array}{c}83.2 \\
\pm \\
2.6\end{array}$ & $\begin{array}{c}56.8^{\mathrm{b}} \\
\pm \\
1.37\end{array}$ & $\begin{array}{c}216^{\mathrm{ab}} \\
\pm \\
7.5\end{array}$ & $\begin{array}{c}113^{\mathrm{a}} \\
\pm \\
5.1\end{array}$ & $\begin{array}{c}120^{\mathrm{a}} \\
\pm \\
3.12\end{array}$ & $\begin{array}{c}62.8^{\mathrm{b}} \\
\pm \\
4.47\end{array}$ \\
\hline$\%$ Change & 0 & -8 & -10 & 2 & 176 & 57 & 67 & 7 & 274 & 108 & 122 & 52 & 477 & 202 & 220 & 68 \\
\hline $\begin{array}{c}1^{\text {st }} \text { week } \\
\text { post } \\
\text { irradiation }\end{array}$ & $\begin{array}{c}38.1^{\mathrm{b}} \\
\pm \\
0.41\end{array}$ & $\begin{array}{c}40.0^{\mathrm{b}} \\
\pm \\
2.52\end{array}$ & $\begin{array}{c}44.6^{\mathrm{b}} \\
\pm \\
2.54\end{array}$ & $\begin{array}{c}37.5^{\mathrm{b}} \\
\pm \\
0 . .85\end{array}$ & $\begin{array}{c}118^{\mathrm{ab}} \\
\pm \\
6.3\end{array}$ & $\begin{array}{c}77.9^{\mathrm{b}} \\
\pm \\
1.52\end{array}$ & $\begin{array}{c}77.8^{\mathrm{b}} \\
\pm \\
3.9\end{array}$ & $\begin{array}{c}61.9^{b} \\
\pm \\
0.72\end{array}$ & $\begin{array}{c}144^{\mathrm{a}} \\
\pm \\
12.5\end{array}$ & $\begin{array}{c}82.1^{\mathrm{b}} \\
\pm \\
1.73\end{array}$ & $\begin{array}{c}87.6 \\
\pm \\
3.47\end{array}$ & $\begin{array}{c}74.3^{\mathrm{b}} \\
\pm \\
4.8\end{array}$ & $\begin{array}{c}239^{\mathrm{ab}} \\
\pm \\
4.8\end{array}$ & $\begin{array}{c}154^{\mathrm{a}} \\
\pm \\
7.6\end{array}$ & $\begin{array}{c}162^{\mathrm{a}} \\
\pm \\
3\end{array}$ & $\begin{array}{c}76.3^{\mathrm{b}} \\
\pm \\
3.5\end{array}$ \\
\hline$\%$ Change & 0 & 5 & 17 & -2 & 207 & 104 & 107 & 62 & 277 & 115 & 130 & 95 & 529 & 305 & 324 & 100 \\
\hline LSD & \multicolumn{16}{|c|}{ 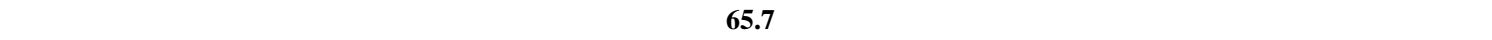 } \\
\hline
\end{tabular}

C: Control; Irr: Irradiation; E: Ehrlich; Res: Resveratrol; Sse: Sodium Selenite; LSD: Least significant difference. Each value represents Mean \pm SE of 6 observations, \%: Percent change from the values of control mice. Values with dissimilar super script letters are considered significantly different at $p<0.05$. a: significant against normal Control group (G1). b: significant against Ehrlich group (G9). 
Table 5: Liver SOD \& CAT activities and liver GSH \& TBARS concentrations in the different animal groups on $1^{\text {st }}$ day and $1^{\text {st }}$ week post irradiation.

\begin{tabular}{|c|c|c|c|c|c|c|c|c|c|c|c|c|c|c|c|c|}
\hline \multirow{3}{*}{ parameter } & \multicolumn{4}{|c|}{ Control groups } & \multicolumn{4}{|c|}{ Irradiated groups } & \multicolumn{4}{|c|}{ Ehrlich groups } & \multicolumn{4}{|c|}{ Ehrlich- Irradiated groups } \\
\hline & $\mathbf{C}$ & Res & Sse & $\begin{array}{c}\text { Res+ } \\
\text { Sse }\end{array}$ & Irr & $\begin{array}{l}\text { Res+ } \\
\text { Irr }\end{array}$ & $\begin{array}{c}\text { Sse+ } \\
\text { Irr }\end{array}$ & $\begin{array}{c}\text { Res+ } \\
\text { Sse+ } \\
\text { Irr }\end{array}$ & $\mathbf{E}$ & $\begin{array}{l}\text { E+ } \\
\text { Res }\end{array}$ & $\begin{array}{l}\text { E+ } \\
\text { Sse }\end{array}$ & $\begin{array}{c}\text { E+ } \\
\text { Res+ } \\
\text { Sse }\end{array}$ & $\begin{array}{l}\text { E+ } \\
\text { Irr }\end{array}$ & $\begin{array}{c}\text { E+ } \\
\text { Res+ } \\
\text { Irr }\end{array}$ & $\begin{array}{c}\text { E+ } \\
\text { Sse+ } \\
\text { Irr }\end{array}$ & $\begin{array}{c}\text { E+ } \\
\text { Res+ } \\
\text { Sse+ } \\
\text { Irr } \\
\end{array}$ \\
\hline & G1 & G2 & G3 & G4 & G5 & G6 & G7 & G8 & G9 & G10 & G11 & G12 & G13 & G14 & G15 & G16 \\
\hline SOD & \multicolumn{16}{|c|}{ (U/min/mg) } \\
\hline $\begin{array}{l}1^{\text {st }} \text { day post } \\
\text { irradiation }\end{array}$ & $\begin{array}{l}9.2^{\mathrm{b}} \\
\pm \\
0.5\end{array}$ & $\begin{array}{c}9.1^{\mathrm{b}} \\
\pm \\
0.5\end{array}$ & $\begin{array}{c}9.13^{\mathrm{b}} \\
\pm \\
0.82\end{array}$ & $\begin{array}{c}8.3^{\mathrm{b}} \\
\pm \\
0.43\end{array}$ & $\begin{array}{c}4.2^{\mathrm{a}} \\
\pm \\
0.5\end{array}$ & $\begin{array}{c}7.7^{\mathrm{ab}} \\
\pm \\
0.4\end{array}$ & $\begin{array}{c}6.8^{\mathrm{ab}} \\
\pm \\
0.3\end{array}$ & $\begin{array}{c}6.9^{\mathrm{ab}} \\
\pm \\
0.2\end{array}$ & $\begin{array}{c}5.4^{\mathrm{a}} \\
\pm \\
0.42\end{array}$ & $\begin{array}{c}7.3^{\mathrm{ab}} \\
\pm \\
0.35\end{array}$ & $\begin{array}{c}7.5^{\mathrm{ab}} \\
\pm \\
0.07\end{array}$ & $\begin{array}{c}8.1^{\mathrm{b}} \\
\pm \\
0.29\end{array}$ & $\begin{array}{c}4.5^{\mathrm{a}} \\
\pm \\
0.29\end{array}$ & $\begin{array}{c}7.5^{\mathrm{ab}} \\
\pm \\
0.4\end{array}$ & $\begin{array}{c}7.3^{\mathrm{ab}} \\
\pm \\
0.2\end{array}$ & $\begin{array}{c}8.3^{\mathrm{b}} \\
\pm \\
0.55\end{array}$ \\
\hline$\%$ Change & 0 & -2 & -1 & -10 & -55 & -17 & -27 & -25 & -41 & -21 & -18 & -12 & -51 & -19 & -21 & -10 \\
\hline $\begin{array}{c}1^{\text {st }} \text { week } \\
\text { post } \\
\text { irradiation }\end{array}$ & $\begin{array}{c}9.1^{\mathrm{b}} \\
\pm \\
0.3\end{array}$ & $\begin{array}{c}9.6^{\mathrm{b}} \\
\pm \\
0.1\end{array}$ & $\begin{array}{c}8.6^{\mathrm{b}} \\
\pm \\
0.09\end{array}$ & $\begin{array}{c}8.2^{\mathrm{b}} \\
\pm \\
0.18\end{array}$ & $\begin{array}{l}3.7^{\mathrm{ab}} \\
\pm \\
0.1\end{array}$ & $\begin{array}{c}4.3^{\mathrm{a}} \\
\pm \\
0.18\end{array}$ & $\begin{array}{l}4.1^{\mathrm{ab}} \\
\pm \\
0.22\end{array}$ & $\begin{array}{c}5.5^{\mathrm{a}} \\
\pm \\
0.2\end{array}$ & $\begin{array}{c}5.1^{\mathrm{a}} \\
\pm \\
0.58\end{array}$ & $\begin{array}{c}6.8^{\mathrm{ab}} \\
\pm \\
0.29\end{array}$ & $\begin{array}{c}6.5^{\mathrm{a}} \\
\pm \\
0.81\end{array}$ & $\begin{array}{c}6.4^{\mathrm{a}} \\
\pm \\
0.74\end{array}$ & $\begin{array}{c}5.2^{\mathrm{a}} \\
\pm \\
0.32\end{array}$ & $\begin{array}{c}7.6^{\mathrm{ab}} \\
\pm \\
0.8\end{array}$ & $\begin{array}{c}7.5^{\mathrm{ab}} \\
\pm \\
0.4\end{array}$ & $\begin{array}{c}7.7^{\mathrm{ab}} \\
\pm \\
0.5\end{array}$ \\
\hline$\%$ Change & 0 & 5 & -5 & -10 & -59 & -53 & -55 & -40 & -44 & -25 & -28 & -30 & -43 & -17 & -18 & -15 \\
\hline LSD & \multicolumn{16}{|c|}{1.5} \\
\hline & G1 & G2 & G3 & G4 & G5 & G6 & G7 & G8 & G9 & G10 & G11 & G12 & G13 & G14 & G15 & G16 \\
\hline CAT & \multicolumn{16}{|c|}{ ( $\mu$ moles consumed $\mathrm{H}_{2} \mathrm{O}_{2} / \mathrm{min} / \mathrm{mg}$ ) } \\
\hline $\begin{array}{l}1^{\text {st }} \text { day post } \\
\text { irradiation }\end{array}$ & $\begin{array}{c}245^{\mathrm{b}} \\
\pm \\
2.8\end{array}$ & $\begin{array}{c}251^{\mathrm{b}} \\
\pm \\
1.36\end{array}$ & $\begin{array}{c}243^{\mathrm{b}} \\
\pm \\
2.19\end{array}$ & $\begin{array}{c}249^{\mathrm{b}} \\
\pm \\
0.99\end{array}$ & $\begin{array}{c}180^{\mathrm{ab}} \\
\pm \\
5.66\end{array}$ & $\begin{array}{c}202^{\mathrm{a}} \\
\pm \\
1.27\end{array}$ & $\begin{array}{c}202^{\mathrm{a}} \\
\pm \\
1.07\end{array}$ & $\begin{array}{c}212^{\mathrm{a}} \\
\pm \\
4.66\end{array}$ & $\begin{array}{c}207^{\mathrm{a}} \\
\pm \\
2.38\end{array}$ & $\begin{array}{c}231^{\mathrm{ab}} \\
\pm \\
1.8\end{array}$ & $\begin{array}{c}229^{\mathrm{ab}} \\
\pm \\
2.4\end{array}$ & $\begin{array}{c}237^{\mathrm{b}} \\
\pm \\
0.71\end{array}$ & $\begin{array}{c}139^{\mathrm{ab}} \\
\pm \\
0.95\end{array}$ & $\begin{array}{c}203^{\mathrm{a}} \\
\pm \\
1.04\end{array}$ & $\begin{array}{c}198^{\mathrm{ab}} \\
\pm \\
1.26\end{array}$ & $\begin{array}{c}215^{\mathrm{a}} \\
\pm \\
3.03\end{array}$ \\
\hline$\%$ Change & 0 & 2 & -1 & 1 & -27 & -18 & -18 & -14 & -15 & -6 & -7 & -3 & -43 & -17 & -19 & -13 \\
\hline $\begin{array}{c}1^{\text {st }} \text { week } \\
\text { post } \\
\text { irradiation }\end{array}$ & $\begin{array}{c}240^{\mathrm{b}} \\
\pm \\
2.64\end{array}$ & $\begin{array}{c}246^{\mathrm{b}} \\
\pm \\
3.69\end{array}$ & $\begin{array}{c}239^{\mathrm{b}} \\
\pm \\
3.47\end{array}$ & $\begin{array}{c}245^{\mathrm{b}} \\
\pm \\
2.23\end{array}$ & $\begin{array}{c}146^{\mathrm{ab}} \\
\pm \\
1.71\end{array}$ & $\begin{array}{c}181^{\mathrm{ab}} \\
\pm \\
1.92\end{array}$ & $\begin{array}{c}178^{\mathrm{ab}} \\
\pm \\
5.45\end{array}$ & $\begin{array}{c}196^{\mathrm{ab}} \\
\pm \\
6.09\end{array}$ & $\begin{array}{c}170^{\mathrm{ab}} \\
\pm \\
2.78\end{array}$ & $\begin{array}{c}192^{\mathrm{ab}} \\
\pm \\
5.6\end{array}$ & $\begin{array}{c}188^{\mathrm{ab}} \\
\pm \\
3.3\end{array}$ & $\begin{array}{c}200^{\mathrm{a}} \\
\pm \\
3.49\end{array}$ & $\begin{array}{c}118^{\mathrm{ab}} \\
\pm \\
1.36\end{array}$ & $\begin{array}{c}161^{\mathrm{ab}} \\
\pm \\
2.4\end{array}$ & $\begin{array}{c}133^{\mathrm{ab}} \\
\pm \\
1.32\end{array}$ & $\begin{array}{c}170^{\mathrm{ab}} \\
\pm \\
3.4\end{array}$ \\
\hline$\%$ Change & 0 & 3 & -0.4 & 2 & -39 & -25 & -26 & -18 & -29 & -20 & -22 & -17 & -51 & -33 & -45 & -30 \\
\hline LSD & \multicolumn{16}{|c|}{14.4} \\
\hline & G1 & G2 & G3 & G4 & G5 & G6 & G7 & G8 & G9 & G10 & G11 & G12 & G13 & G14 & G15 & G16 \\
\hline GSH & \multicolumn{16}{|c|}{ (mg GSH/ gm) } \\
\hline $\begin{array}{l}1^{\text {st }} \text { day post } \\
\text { irradiation }\end{array}$ & $\begin{array}{c}36.5 \\
\pm \\
1.6\end{array}$ & $\begin{array}{c}34.7 \\
\pm \\
0.4\end{array}$ & $\begin{array}{c}33.7 \\
\pm \\
1.7\end{array}$ & $\begin{array}{c}37.1^{\mathrm{b}} \\
\pm \\
0.8\end{array}$ & $\begin{array}{c}29.2^{\mathrm{ab}} \\
\pm \\
2.1\end{array}$ & $\begin{array}{c}33.7 \\
\pm \\
0.9\end{array}$ & $\begin{array}{c}32.1^{\mathrm{a}} \\
\pm \\
0.9\end{array}$ & $\begin{array}{c}35.9 \\
\pm \\
2.0\end{array}$ & $\begin{array}{c}33.7 \\
\pm \\
0.9\end{array}$ & $\begin{array}{c}35.7 \\
\pm \\
0.5\end{array}$ & $\begin{array}{c}34.7 \\
\pm \\
0.5\end{array}$ & $\begin{array}{c}37.3^{\mathrm{b}} \\
\pm \\
1.3\end{array}$ & $\begin{array}{c}24.9^{\mathrm{ab}} \\
\pm \\
2.1\end{array}$ & $\begin{array}{c}31.2^{\mathrm{a}} \\
\pm \\
0.9\end{array}$ & $\begin{array}{c}30.4^{\mathrm{a}} \\
\pm \\
1.5\end{array}$ & $\begin{array}{c}34.2^{\mathrm{b}} \\
\pm \\
0.6\end{array}$ \\
\hline$\%$ Change & 0 & -5 & -8 & 2 & -20 & -8 & -12 & -2 & -8 & -2 & -5 & 2 & -32 & -15 & -17 & -6 \\
\hline $\begin{array}{c}1^{\text {st }} \text { week } \\
\text { post } \\
\text { irradiation }\end{array}$ & $\begin{array}{c}36.8 \\
\pm \\
1.4\end{array}$ & $\begin{array}{c}35.1 \\
\pm \\
0.2\end{array}$ & $\begin{array}{c}34.4 \\
\pm \\
0.5\end{array}$ & $\begin{array}{c}37.7^{\mathrm{b}} \\
\pm \\
0.8\end{array}$ & $\begin{array}{c}24.8^{\mathrm{ab}} \\
\pm \\
0.5\end{array}$ & $\begin{array}{c}30.5^{\mathrm{a}} \\
\pm \\
0.4\end{array}$ & $\begin{array}{c}30^{\mathrm{ab}} \\
\pm \\
0.7\end{array}$ & $\begin{array}{c}32.2^{\mathrm{a}} \\
\pm \\
2.1\end{array}$ & $\begin{array}{c}33.9 \\
\pm \\
1\end{array}$ & $\begin{array}{c}35.2 \\
\pm \\
0.3\end{array}$ & $\begin{array}{c}34.7 \\
\pm \\
0.2\end{array}$ & $\begin{array}{c}36.5 \\
\pm \\
0.9\end{array}$ & $\begin{array}{c}20.9^{\mathrm{ab}} \\
\pm \\
0.9\end{array}$ & $\begin{array}{c}30.2^{\mathrm{a}} \\
\pm \\
1.3\end{array}$ & $\begin{array}{c}29.4^{\mathrm{a}} \\
\pm \\
2.0\end{array}$ & $\begin{array}{c}33.3^{\mathrm{b}} \\
\pm \\
0.6\end{array}$ \\
\hline$\%$ Change & 0 & -5 & -7 & 3 & -33 & -17 & -18 & -13 & -8 & -4 & -6 & -1 & -43 & -18 & -20 & -10 \\
\hline LSD & \multicolumn{16}{|c|}{4.4} \\
\hline & G1 & G2 & G3 & G4 & G5 & G6 & G7 & G8 & G9 & G10 & G11 & G12 & G13 & G14 & G15 & G16 \\
\hline TBARS & \multicolumn{16}{|c|}{$(\mathrm{nmol} / \mathrm{g})$} \\
\hline $\begin{array}{l}1^{\text {st }} \text { day post } \\
\text { irradiation }\end{array}$ & $\begin{array}{c}118^{\mathrm{b}} \\
\pm \\
2.89\end{array}$ & $\begin{array}{c}106^{\mathrm{ab}} \\
\pm \\
1.89\end{array}$ & $\begin{array}{c}112^{\mathrm{b}} \\
\pm \\
1.87\end{array}$ & $\begin{array}{c}117^{\mathrm{b}} \\
\pm \\
3.2\end{array}$ & $\begin{array}{c}235^{\mathrm{ab}} \\
\pm \\
6\end{array}$ & $\begin{array}{c}176^{\mathrm{ab}} \\
\pm \\
3.9\end{array}$ & $\begin{array}{c}202^{\text {ab }} \\
\pm \\
2.14\end{array}$ & $\begin{array}{c}212^{\mathrm{ab}} \\
\pm \\
12.5\end{array}$ & $\begin{array}{c}272^{\mathrm{a}} \\
\pm \\
13.1\end{array}$ & $\begin{array}{c}210^{\mathrm{ab}} \\
\pm \\
3.4\end{array}$ & $\begin{array}{c}217^{\mathrm{ab}} \\
\pm \\
1.6\end{array}$ & $\begin{array}{c}244^{\mathrm{ab}} \\
\pm \\
2.89\end{array}$ & $\begin{array}{c}334^{\mathrm{ab}} \\
\pm \\
9.8\end{array}$ & $\begin{array}{c}243^{\mathrm{ab}} \\
\pm \\
5.24\end{array}$ & $\begin{array}{c}285^{\mathrm{ab}} \\
\pm \\
5.4\end{array}$ & $\begin{array}{c}255^{\text {ab }} \\
\pm \\
8.4\end{array}$ \\
\hline$\%$ Change & 0 & -10 & -5 & -1 & 99 & 49 & 72 & 80 & 131 & 78 & 85 & 107 & 184 & 106 & 142 & 117 \\
\hline $\begin{array}{c}1^{\text {st }} \text { week } \\
\text { post } \\
\text { irradiation }\end{array}$ & $\begin{array}{c}119^{\mathrm{b}} \\
\pm \\
3.61\end{array}$ & $\begin{array}{c}117^{\mathrm{b}} \\
\pm \\
2.48\end{array}$ & $\begin{array}{c}119^{\mathrm{b}} \\
\pm \\
2.45\end{array}$ & $\begin{array}{c}122^{\mathrm{b}} \\
\pm \\
5\end{array}$ & $\begin{array}{c}283^{\text {ab }} \\
\pm \\
4.9\end{array}$ & $\begin{array}{c}212^{\mathrm{ab}} \\
\pm \\
0.33\end{array}$ & $\begin{array}{c}223^{\mathrm{ab}} \\
\pm \\
5.1\end{array}$ & $\begin{array}{c}254^{\mathrm{ab}} \\
\pm \\
6.6\end{array}$ & $\begin{array}{c}304^{\mathrm{ab}} \\
\pm \\
9.5\end{array}$ & $\begin{array}{c}241^{\mathrm{ab}} \\
\pm \\
6.7\end{array}$ & $\begin{array}{c}264^{\mathrm{ab}} \\
\pm \\
2.58\end{array}$ & $\begin{array}{c}309^{\mathrm{ab}} \\
\pm \\
8.4\end{array}$ & $\begin{array}{c}357^{\mathrm{ab}} \\
\pm \\
5.4\end{array}$ & $\begin{array}{c}236^{\mathrm{ab}} \\
\pm \\
6.9\end{array}$ & $\begin{array}{c}289^{\mathrm{ab}} \\
\pm \\
18.6\end{array}$ & $\begin{array}{c}281^{\mathrm{ab}} \\
\pm \\
8.16\end{array}$ \\
\hline$\%$ Change & 0 & -2 & -0.3 & 2 & 137 & 77 & 87 & 113 & 154 & 102 & 121 & 159 & 199 & 98 & 142 & 136 \\
\hline LSD & \\
\hline
\end{tabular}

C: Control; Irr: Irradiation; E: Ehrlich; Res: Resveratrol; Sse: Sodium Selenite; LSD: Least significant difference. Each value represents Mean \pm SE of 6 observations, \%: Percent change from the values of control mice. Values with dissimilar super script letters are considered significantly different at $p<0.05$. a: significant against normal Control group (G1). b: significant against Ehrlich group (G9). 
Tumor TBARS level

Data represented in Table (6) demonstrate the concentration of TBARS was increased on $1^{\text {st }}$ week post irradiation when compared with its corresponding level on $1^{\text {st }}$ day post irradiation. The concentration of TBARS in E+Irr mice group was significantly increased as compared to Ehrlich mice group. Treatment of E and
E+Irr mice groups with Res, Sse or Res+Sse induced significant increase in tumor TBARS concentration on $1^{\text {st }}$ day and $1^{\text {st }}$ week post irradiation, compared to Ehrlich group. The increase was more significant on $1^{\text {st }}$ week post irradiation. The results revealed that Res + Sse mice group have the most tumor TBARS concentration increment compared to Res or Sse mice group alone.

Table 6: Tumor SOD \& CAT activities and tumor GSH \& TBARS concentrations in the different animal groups on $1^{\text {st }}$ day and $1^{\text {st }}$ week post irradiation.

\begin{tabular}{|c|c|c|c|c|c|c|c|c|}
\hline \multirow{3}{*}{ parameter } & \multicolumn{4}{|c|}{ Ehrlich animal groups } & \multicolumn{4}{|c|}{ Ehrlich-Irradiated animal groups } \\
\hline & $\mathbf{E}$ & $\begin{array}{l}\text { E+ } \\
\text { Res }\end{array}$ & $\begin{array}{l}\text { E+ } \\
\text { Sse }\end{array}$ & $\begin{array}{c}\text { E+ Res+ } \\
\text { Sse }\end{array}$ & $\begin{array}{l}\text { E+ } \\
\text { Irr }\end{array}$ & $\begin{array}{c}\text { E+ Res+ } \\
\text { Irr }\end{array}$ & $\begin{array}{c}\text { E+ Sse+ } \\
\text { Irr }\end{array}$ & $\begin{array}{l}\text { E+ Res+ } \\
\text { Sse+ Irr }\end{array}$ \\
\hline & G9 & G10 & G11 & G12 & G13 & G14 & G15 & G16 \\
\hline SOD & \multicolumn{8}{|c|}{ (U/min/mg) } \\
\hline $\begin{array}{l}1^{\text {st }} \text { day post } \\
\text { irradiation }\end{array}$ & $\begin{array}{c}5.8 \\
\pm \\
0.26 \\
\end{array}$ & $\begin{array}{c}5.5 \\
\pm \\
0.22 \\
\end{array}$ & $\begin{array}{c}5.7 \\
\pm \\
0.15 \\
\end{array}$ & $\begin{array}{c}4.1^{\mathrm{b}} \\
\pm \\
0.03 \\
\end{array}$ & $\begin{array}{c}4.9^{\mathrm{b}} \\
\pm \\
0.025 \\
\end{array}$ & $\begin{array}{c}3.9^{\mathrm{b}} \\
\pm \\
0.1 \\
\end{array}$ & $\begin{array}{c}4.2^{\mathrm{b}} \\
\pm \\
0.04 \\
\end{array}$ & $\begin{array}{c}3.3^{\mathrm{b}} \\
\pm \\
0.04 \\
\end{array}$ \\
\hline$\%$ Change & 0 & -6 & -2 & -29 & -16 & -33 & -28 & -43 \\
\hline $\begin{array}{l}1^{\text {st }} \text { week post } \\
\text { irradiation }\end{array}$ & $\begin{array}{c}6.1 \\
\pm \\
0.04\end{array}$ & $\begin{array}{c}6 \\
\pm \\
0.15\end{array}$ & $\begin{array}{c}6.4^{\mathrm{b}} \\
\pm \\
0.06\end{array}$ & $\begin{array}{c}3.9^{b} \\
\pm \\
0.03\end{array}$ & $\begin{array}{c}3.7^{\mathrm{b}} \\
\pm \\
1.03\end{array}$ & $\begin{array}{c}3.2^{b} \\
\pm \\
0.06\end{array}$ & $\begin{array}{c}3.4^{\mathrm{b}} \\
\pm \\
0.09\end{array}$ & $\begin{array}{c}1.9^{b} \\
\pm \\
0.03\end{array}$ \\
\hline \% Change & 0 & -1 & 6 & -36 & -39 & -47 & -43 & -68 \\
\hline LSD & \multicolumn{8}{|c|}{0.6} \\
\hline CAT & \multicolumn{8}{|c|}{ ( $\mu$ moles consumed $\mathrm{H}_{2} \mathrm{O}_{2} / \mathrm{min} / \mathrm{mg}$ ) } \\
\hline $\begin{array}{l}1^{\text {st }} \text { day post } \\
\text { irradiation }\end{array}$ & $\begin{array}{c}126.30 \\
\pm \\
0.51 \\
\end{array}$ & $\begin{array}{c}92.17^{\mathrm{b}} \\
\pm \\
4.71 \\
\end{array}$ & $\begin{array}{c}110.6^{\mathrm{b}} \\
\pm \\
1.91 \\
\end{array}$ & $\begin{array}{c}87.73^{\mathrm{b}} \\
\pm \\
2.88 \\
\end{array}$ & $\begin{array}{c}62.7^{b} \\
\pm \\
2.09 \\
\end{array}$ & $\begin{array}{c}56.1^{b} \\
\pm \\
3.56\end{array}$ & $\begin{array}{c}48.63^{b} \\
\pm \\
4.05 \\
\end{array}$ & $\begin{array}{c}41.43^{b} \\
\pm \\
2.14 \\
\end{array}$ \\
\hline$\%$ Change & & -27 & -12 & -31 & -50 & -56 & -61 & -67 \\
\hline $\begin{array}{l}1^{\text {st }} \text { week post } \\
\text { irradiation }\end{array}$ & $\begin{array}{c}134.5 \\
\pm \\
2.37 \\
\end{array}$ & $\begin{array}{c}114^{\mathrm{b}} \\
\pm \\
2.7 \\
\end{array}$ & $\begin{array}{c}123.53 \\
\pm \\
0.55 \\
\end{array}$ & $\begin{array}{c}111.3^{\mathrm{b}} \\
\pm \\
1.45 \\
\end{array}$ & $\begin{array}{c}39.5^{\mathrm{b}} \\
\pm \\
2.91 \\
\end{array}$ & $\begin{array}{c}42.37^{b} \\
\pm \\
2.25 \\
\end{array}$ & $\begin{array}{c}46.37^{\mathrm{b}} \\
\pm \\
1.76\end{array}$ & $\begin{array}{c}31.1^{\mathrm{b}} \\
\pm \\
0.98 \\
\end{array}$ \\
\hline$\%$ Change & & -16 & -8 & -17 & -71 & -69 & -66 & -77 \\
\hline LSD & \multicolumn{8}{|c|}{8.2} \\
\hline GSH & \multicolumn{8}{|c|}{ (mg GSH/ gm) } \\
\hline $\begin{array}{l}1^{\text {st }} \text { day post } \\
\text { irradiation }\end{array}$ & $\begin{array}{c}30.7 \\
\pm \\
1.4 \\
\end{array}$ & $\begin{array}{c}21.6^{\mathrm{b}} \\
\pm \\
1.5 \\
\end{array}$ & $\begin{array}{c}22.8^{\mathrm{b}} \\
\pm \\
1.46 \\
\end{array}$ & $\begin{array}{c}18.9^{\mathrm{b}} \\
\pm \\
0.86\end{array}$ & $\begin{array}{c}29.6 \\
\pm \\
0.97 \\
\end{array}$ & $\begin{array}{c}19.63^{\mathrm{b}} \\
\pm \\
0.87 \\
\end{array}$ & $\begin{array}{c}20.87^{\mathrm{b}} \\
\pm \\
1.21\end{array}$ & $\begin{array}{c}16.20^{\mathrm{b}} \\
\pm \\
0.61 \\
\end{array}$ \\
\hline$\%$ Change & 0 & -30 & -26 & -39 & -4 & -36 & -32 & -47 \\
\hline $\begin{array}{l}1^{\text {st }} \text { week post } \\
\text { irradiation }\end{array}$ & $\begin{array}{c}32.80 \\
\pm \\
1.01 \\
\end{array}$ & $\begin{array}{c}25.1 \\
\pm \\
1.1 \\
\end{array}$ & $\begin{array}{c}29.2 \\
\pm \\
1.34 \\
\end{array}$ & $\begin{array}{c}22.73^{\mathrm{b}} \\
\pm \\
1.62 \\
\end{array}$ & $\begin{array}{c}21.1^{\mathrm{b}} \\
\pm \\
1.04 \\
\end{array}$ & $\begin{array}{c}16.97^{\mathrm{b}} \\
\pm \\
0.99 \\
\end{array}$ & $\begin{array}{c}19.4^{\mathrm{b}} \\
\pm \\
0.81\end{array}$ & $\begin{array}{c}14.9^{\mathrm{b}} \\
\pm \\
0.74 \\
\end{array}$ \\
\hline$\%$ Change & 0 & -23 & -12 & -31 & -36 & -48 & -41 & -55 \\
\hline LSD & \multicolumn{8}{|c|}{7.97} \\
\hline TBARS & \multicolumn{8}{|c|}{$(\mathbf{n m o l} / \mathrm{g})$} \\
\hline $\begin{array}{l}1^{\text {st }} \text { day post } \\
\text { irradiation }\end{array}$ & $\begin{array}{c}71.7 \\
\pm \\
4.2 \\
\end{array}$ & $\begin{array}{c}130.6^{\mathrm{b}} \\
\pm \\
2.16 \\
\end{array}$ & $\begin{array}{c}100.6^{\mathrm{b}} \\
\pm \\
3.35 \\
\end{array}$ & $\begin{array}{c}112.2^{\mathrm{b}} \\
\pm \\
3.1 \\
\end{array}$ & $\begin{array}{c}134.4^{\mathrm{b}} \\
\pm \\
4.42 \\
\end{array}$ & $\begin{array}{c}178.9^{b} \\
\pm \\
4 \\
\end{array}$ & $\begin{array}{c}155.3^{\mathrm{b}} \\
\pm \\
4.6\end{array}$ & $\begin{array}{c}265.6^{\mathrm{b}} \\
\pm \\
7.7 \\
\end{array}$ \\
\hline$\%$ Change & 0 & 82 & 40 & 56 & 87 & 149 & 117 & 270 \\
\hline $\begin{array}{l}1^{\text {st }} \text { week post } \\
\text { irradiation }\end{array}$ & $\begin{array}{c}82.5 \\
\pm \\
4.2 \\
\end{array}$ & $\begin{array}{c}158.2^{b} \\
\pm \\
2.7 \\
\end{array}$ & $\begin{array}{c}130.9^{b} \\
\pm \\
5.4 \\
\end{array}$ & $\begin{array}{c}162.7^{\mathrm{b}} \\
\pm \\
5.4 \\
\end{array}$ & $\begin{array}{c}173.8^{\mathrm{b}} \\
\pm \\
4.2 \\
\end{array}$ & $\begin{array}{c}264.9^{\mathrm{b}} \\
\pm \\
5.14 \\
\end{array}$ & $\begin{array}{c}225.4^{\mathrm{b}} \\
\pm \\
3.5\end{array}$ & $\begin{array}{c}287.1^{\mathrm{b}} \\
\pm \\
2.9 \\
\end{array}$ \\
\hline$\%$ Change & 0 & 92 & 59 & 97 & 110 & 222 & 173 & 249 \\
\hline LSD & \multicolumn{8}{|c|}{10.7} \\
\hline
\end{tabular}

Irr: Irradiation; E: Ehrlich; Res: Resveratrol; Sse: Sodium Selenite; LSD: Least significant difference. Each value represents Mean \pm SE of 6 observations. Values with dissimilar super script letters are considered significantly different at $p<0.05$. a: significant against normal Control group (G1). b: significant against Ehrlich group (G9). c: significant against E+Irr. 


\section{Discussion}

Metastatic spread of tumor cells cause cancer deaths. Moreover, clinical findings providing a pathway for tumor cell dissemination, so tumor associated neovascularization [angiogenesis] is a key component of metastatic spread ${ }^{[28]}$. Angiogenesis, the growth of new blood vessels from an existing vasculature, is a critical process in the formation of solid tumor growth beyond 1-2 $\mathrm{mm}$ in diameter. The Angiogenic process is a balance between stimulatory and inhibitory switch allowing tumor to induce microvessels formation from the surrounding host vasculature ${ }^{[2]}$.

Data represented in this study revealed a significant increases $[p<0.05]$ in TNF- $\alpha$ level and MMP-2, MMP-9 and LDH activities. The increase in TNF- $\alpha$ expression could be concerned in its role in neovascularization process. TNF- $\alpha$ is a major inflammatory mediator that induces multiple changes in Endothelial cell [EC] including induction of adhesion molecules, integrins, and matrix metalloproteinases [MMPs] ${ }^{[29]}$.

Altered levels of pro-inflammatory and pro-angiogenic factors are observed in various forms of cancer, TNF- $\alpha$ expression was related to differentiation, invasiveness, and angiogenesis of various tumor ${ }^{[30]}$.

Matrix metalloproteinases [MMPs] are a family of enzymes involved in many physiological processes involving matrix remodeling, and appear to be essential in angiogenesis, tumor cell invasion and metastasis ${ }^{[31]}$. These are zinc-dependent responsible for extracellular matrix $[\mathrm{ECM}]$ degradation and secreted in inactive proenzymatic forms. MMP-2 \& 9 [gelatinases A \& B] were found to be over-expressed in many invasive tumor cells. Several experiments have confirmed the key role of these enzymes in angiogenesis ${ }^{[32]}$.

Data represented in this work demonstrate similar pattern in MMP-2 and MMP-9 changes. The significant increase in MMP-2 and MMP-9 activities in EAC bearing mice could be attributed to TNF- $\alpha$ level. TNF- $\alpha$ stimulated MMP-2 and MMP-9 activities in human corneal epithelial cells via the activation of focal adhesion kinase $[\mathrm{FAK}] /$ extracellular regulated protein kinase [ERK] signaling ${ }^{[33]}$. In addition, the experimental data revealed a significant increase $[p<0.05]$ in LDH concentration of EAC bearing mice group during $1^{\text {st }}$ day and $1^{\text {st }}$ week post irradiation. As a diagnostic and prognostic marker, serum LDH has previously been reported mainly as a marker of ominous outcome in cancer patients, including a variety of solid tumors ${ }^{[34]}$.

The presented data shows that the increases in TNF- $\alpha$, MMP-2, MMP-9 and LDH are accompanied with increases in tumor volume. The neovasculaturization enhances the ability of the tumor to grow as well as increases its invasiveness and metastatic ability ${ }^{[35]}$. Moreover, the increase in tumor volume in mice bearing EAC is associated with significant depletion in antioxidant parameters SOD, CAT and GSH. Tumor GSH depletion may have increased the sensitivity of tumor to radiation so, the initial complete cell killing might have occurred at the early stages of tumor development ${ }^{[36]}$. Depletion of GSH can lead to increase lipid peroxidation and cell damage while an increase in GSH level enhances antioxidant protection and cell function ${ }^{[37]}$.

The present data reveal marked depletion in GSH content accompanied by significant inhibition of GSH dependent enzymes of tumor-bearing mice group, either exposed or not to irradiation. The depletion in GSH content has been previously reported in tissues of animals exposed to irradiation ${ }^{[38]}$ and in irradiation-treated mice bearing tumor ${ }^{[39]}$. In addition, there is a close correlation between depletion of GSH and antioxidant enzymes and the increase in lipid peroxidation ${ }^{[38]}$.

The loss of mitochondria in tumor host could be responsible for the decrease in total SOD activity in liver tissues of the tumor host ${ }^{[40]}$. When the oxidative damage is extreme as a result of tumor growth ROS scavenging system such as SOD, GSH and CAT are degraded which in turn lead to increase in free radicals which cause oxidative stress. Free radicals and oxidative stress in turn increase the expression of TNF- $\alpha$ which responsible for the successive steps in the angiogenesis process leading to continuous tumor growth.

The present study interests in control of angiogenic process as a promising approach in overwhelming cancer, the antiangiogenic capacity of Resveratrol in combination with Sodium selenite was examined, and administration of Resveratrol and /or Sodium selenite to mice bearing tumor and/or $\gamma$-irradiated induced improvement in the level of angiogenic activators TNF$\alpha$, MMP2, MMP9 and LDH when compared with their correspondence values in EAC mice.

The present results are in harmony with those of Liu $\boldsymbol{e t}$ al., who reported that resveratrol inhibits the invasiveness of diverse cancer cells by reducing the expression and activity of matrix metalloproteinase [MMP-2\& MMP-9], involved in ECM degradation ${ }^{[41]}$, and with those of Garvin et al., who affirmed that intratumoral, peritumoral or intraperitoneal administration of resveratrol significantly arrested tumor growth in vivo ${ }^{[42]}$.

Resveratrol is a fat-soluble compound exists in cis-and trans-stereoisomeric forms trans-resveratrol is more active and can undergo isomerization to the cis-form when heated or exposed to ultraviolet irradiation ${ }^{[43]}$.

The present data are in accordance with those of Luo $\boldsymbol{e t}$ al., who examined the pre-treatment with resveratrol prior to ionizing radiation exposure of resveratrol radiosensitives human cervical tumor cell lines and nonsmall cell lung cancer [NSCLC] cells enhances tumor cell killing by ionizing radiation in a dose dependent manner ${ }^{[44]}$.

Resveratrol possesses three phenolic groups and acts as a free radical scavenger by transferring the proton from its phenolic group to the free radicals ${ }^{[45]}$. It has documented antitumor function but also acts synergistically with other agents from the same class ${ }^{[45]}$, and contributed to a putative anticancer action, such as antioxidant activity ${ }^{[46]}$, proapoptotic capacity ${ }^{[47]}$, antiproliferative ${ }^{[48]}$ and 
antiangiogenic activities ${ }^{\mathbf{4 9}]}$.

Zhang $\boldsymbol{e t}$ al. reported that resveratrol inhibited TNF- $\alpha$ induced apoptosis and rescued the inhibition of TNF- $\alpha$ in osteogenic differentiation of BM-MSCs at an early stage, when the TNF- $\alpha$-activated NF- $\kappa \mathrm{B}$ signaling was suppressed by resveratrol, and it is a good candidate for further research as an anti-inflammatory or anti TNF- $\alpha$ agent in bone repair under in vivo inflammatory microenvironment ${ }^{[50]}$.

Selenium could inhibit the angiogenesis of hepatocarcinoma in rats, by down regulating the expression of TNF- $\alpha$ and VEGF ${ }^{[41]}$, and it also leads to inhibition of TNF- $\alpha$ in human umbilical vein endothelial cells [HUVECs] and in turn lead to suppression of MMP-2 \&MMP-9 activities ${ }^{[51]}$. Sodium selenite and other different selenium forms could be able to inhibit cancer metastasis and primary tumor growth in multiple types of cancer in animals ${ }^{[52]}$.

Many investigators have reported that the inhibition of antioxidant systems in blood and tissues of mice and rats accompanied by an increase in lipid peroxide products after irradiation exposure ${ }^{[53]}$ and in irradiated mice bearing EAC ${ }^{[39]}$. On the other hand, a number of studies have indicated that tumor growth can cause antioxidant disturbances in certain tissues of the tumor host ${ }^{[39]}$.

In fact, tumor development might be responsible for the liver antioxidant depletion and also the increased concentration of lipid peroxidation products [54] Furthermore, the generation of lipid peroxide in mice liver after exposure to $\gamma$-irradiation could result from inactivation of antioxidant activities by irradiationinduced production of ROS. Elapsed Lipid peroxidation apparently can be initiated by hydrogen abstraction from lipid molecules by lipid radiolysis products ${ }^{[55]}$; this leads to permeability changes due to alterations of membrane proteins and polysaccharides. It was also reported that the level of increase in [LPx] after irradiation is in proportion to radiation dose and elapsed time ${ }^{[56]}$. When the oxidative damage is extreme as a result of tumor growth and/or $\gamma$-irradiation, ROS scavenging enzymes such as (SOD\& CAT) and GSH are degraded ${ }^{[57]}$. Free radical and oxidative stress in turn increase the expression of TNF- $\alpha$ which is responsible for the successive steps in the angiogenesis process leading to continuous tumor growth.

Gamma-radiation (3 Gy) exposure increased the levels of [ROS], percent apoptotic cells and decreased the mitochondrial membrane potential in human peripheral blood lymphocytes ${ }^{[58]}$.

The present data also, showed significant amelioration of the antioxidant parameters CAT, SOD and GSH in EAC mice treated with resveratrol and/or sodium selenite $\gamma$-irradiated or not when compared with their equivalents values in EAC mice group. It could be postulated that, resveratrol and/or sodium selenite could inhibit cancer growth through controlling the angiogenic process. The increase in the activities and concentration of these antioxidants after the administration of resveratrol may be due to the direct effect of resveratrol.

\section{References}

1) Cantor, J. R. and Sabatini, D. M. (2012). Cancer cell metabolism: one hallmark, many faces. Cancer Discov., 2:881-898.

2) Mehmet, S., Emel, S. and Gümüs, S. (2012). Effects of lycopene and resveratrol on human umbilical vein endothelial cells in vitro under angiogenic stimulation. Acta. Histochemica., 1(14) : 94-100.

3) Goel, S., Duda, D. G., Xu, L., Munn, L. L. and Boucher, Y. (2011). Normalization of the vasculature for the treatment of cancer and other diseases. Physiol. Rev., 91(3): 1071-1121.

4) Shiva Shankar, T. V., Sulka, B., Hubert, P., Hubaux, R. and Delvenne, P. (2015). NHydroxy-6-(5-Nitro-Naphtalimide)-Hexanamide inhibits Lysine Deacetylation, Mitigates Angiogenesis and Reduces Tumor Growth. $J$. Cancer Sci., 2(1): 11.

5) Liekens, S., De Clercq, E. and Neyts, J. (2001). Angiogenesis: regulators and clinical applications. Biochem. Pharmacol., 1;61(3):253-270.

6) Hanahan, D. and Folkman, J. (1996). Patterns and emerging mechanisms of the angiogenic switch during tumorigenesis. Cell, 86(3):353-364.

7) Pandey, K. B. and Rizvi, S. I. (2011). Antioxidative action of resveratrol: Implications for human health. Arabian Journal of Chemistry, 4: 293-298.

8) Bhat, T. and Singh, R. (2008). Tumor angiogenesis - a potential target in cancer chemoprevention. Food Chem. Toxicol., 46: 1334-1345.

9) Milardi, G. L., Stringaro, A., Colone, M., Bonicontro, A. and Risuleo, G. (2014). The cell membrane is the main target of resveratrol as shown by interdisciplinary biomolecular/cellular and biophysical approaches. J. Membr. Biol., 247: 1-8.

10) Gulcin, L. (2010). Antioxidant properties of resveratrol: a structure-activity insight. Innov. Food Sci. Emerg. Tech., 11: 210-218.

11) Bai, Y., Mao, Q. Q., Qin, J., Zheng, X. Y., Wang, Y. B., Yang, K., Shen, H. F. and Xie, L. P. (2010). Resveratrol induces apoptosis and cell cycle arrest of human T24 bladder cancer cells in vitro and inhibits tumor growth in vivo. Cancer Sci., 101:488-493.

12) Wesolowska, O., Kuzdal, M., Strancar, J. and Michalak, K. (2009). Interaction of the chemopreventive agent resveratrol and its metabolite, piceatannol, with model membranes, Biochim. Biophys. Acta., 1788: 1851-1860.

13) Mosmann, T. (1983). Rapid colorimetric assay for cellular growth and survival: application to proliferation and cytotoxicity tests. J. Immunol. Methods, 65, 55-63.

14) Kralova, V., Benešova, S., Ervinka, M. C. and Rudolf, E. (2012). Selenite-induced apoptosis and autophagy in colon cancer cells. Toxicology in Vitro, 26: $258-268$. 
15) Kumar, P. P. and Kuttan, G. (2011). Nomilin inhibits tumor-specific angiogenesis by downregulating VEGF, NO and proinflammatory cytokine profile and also by inhibiting the activation of MMP-2 and MMP-9. European Journal of Pharmacology, 668: 450-458.

16) Fotakis, G. and Timbrell, J. A. (2006). In vitro cytotoxicity assays: comparison of $\mathrm{LDH}$, neutral red. MTT and protein assay in hepatoma cell lines following exposure to cadmium chloride. Toxicol. Lett., 160: 171-177.

17) Papadopoulos, D., Kimler, B. F., Estes, N. C. and Durham, F. J. (1989). Growth delay effect of combined interstitial hyperthermia and branchytherapy in a rat solid tumor model. Anticancer Research, 9:45-47.

18) Busquets, S., Ametller, E., Fuster, G., Olivan, M., Raab, V., Argilés, J. M. and López-Soriano, F. J. (2007). Resveratrol, a natural diphenol, reduces metastatic growth in an experimental cancer model. Cancer Lett., 245(1-2):144-148

19) Poirier, K. A. and Milner, J. A. (1983). Factors influencing the antitumorigenic properties of selenium in mice, J. Nutr., 113(11):2147-2154

20) Weichselbaum, T. E. (1946). An accurate and rapid method for determination of protein in small amount of blood serum and plasma. Am. Clin. Path., 16:4048.

21) Birkedal-Hansen, H. and Taylor, R. E. (1982). Detergent activation latent collagenase and resolution of its molecules. Biochem. Biophys. Res. Commun., 107:1173-1178.

22) Drew, P. D. and Chavis, J. A. (2001). The cyclopentone prostaglandin 15-deoxy-Delta $(12,14)$ prostaglandin $\mathrm{J} 2$ represses nitric oxide, TNF-alpha, and IL-12 production by microglial cells. $J$. Neuroimmunol., 15(1-2):28-35.

23) Young, D. S. (2001). Effects of drugs on clinical lab. Tests, $4^{\text {th }}$ ed .Washington, D: C.AACC press.

24) Minami, M. and Yoshikawa, H. (1979). A simplified assay method of superoxide dismutase activity for clinical use. Clin. Chim. Acta., 92(3): 337-342.

25) Sinha, A. K. (1972). Colorimetric assay of catalase. J.Anal. Biochem., 47(2):389-394.

26) Beutler, E., Duron, O. and Kelly, B. M. (1963). Improved method for determination of blood glutathione. Lab. Clin. Med., 61(5):882-888.

27) Yoshioka, T., Kawada, K., Shimada, T. and Mori, M. (1979). Lipid peroxidation in maternal and cord blood and protective mechanism against activated oxygen toxicity in the blood. Am. J. Obstet. Gynecol., 135: 372-376.

28) Pepper, M. S. (2001). Lymphangiogenesis and tumor metastasis: myth or reality? Clin. Cancer. Res., 7(3):462-8.

29) Song, K. F., Zhang, H. and junShang, Z. (2012). Tumor necrosisfactor- $\alpha$ enhanced fusions between oral squamous cell carcinoma cells and endothelial cells via VCAM-1/VLA-4pathway. Experimental cell research, 318:1707-1715

30) Feng, Ch., Med, M. and Wang, H. (2011). Expression of pigment epithelium-derived factor and tumor necrosis factor- $\alpha$ is correlated in bladder tumor and is related to tumor angiogenesis. Urologic Oncology: Seminars and Original Investigations. 6:20-30.

31) Löffek, S., Schilling, O. and Franzke, C. W. (2011). Series "matrix metalloproteinases in lung health and disease": Biological role of matrix metalloproteinases: a critical balance. Eur. Respir. J., 38(1):191-208

32) Gong, Y., Chippada-Venkata, U. D. and Oh, W. K. (2014). Roles of matrix metalloproteinases and their natural inhibitors in prostate cancer progression. Cancers (Basel), 6(3):1298-1327.

33) Yang, K., Tagawa, Ch, Matsufuji, H. and Chino, M. (2012). Dietary apigenin regulates high glucose and hypoxic reoxygenation-induced reductions in apelin expression in human endothelial cells. Journal of Nutritional Biochemistry, 23: 929-936.

34) Tredan, O., Ray-Coquard, I. and Chvetzoff, G. (2011). Validation of prognostic scores for .survival in cancer patients beyond first-line therapy. $B M C$ Cancer, 11:95-103.

35) Xu, W., Liu, L. Z., Loizidou, M. and Ahmed, M. (2002). The role of nitric oxide in cancer. Cell Res., 12(5-6):311-320.

36) Jagetia, G. C. and Venkatesha, V. A. K. (2005). Enhancement of Radiation Effect by Aphanamixis polystachya in mice Transplanted with Ehrlich Ascites Carcinoma. Biological and Pharmaceutical Bulletin, 28(1):69-77.

37) Neal, R. M. (2003). Density modeling and clustering using Dirichlet diffusion trees. In. J. M. Bernardo, M. J. Bayarri, J. O. Berger, A. P. Dawid, D. Heckerman, A. F. M. Smith and M. West (editors) Bayesian Statistics, 7:619-629.

38) Devi, P. U. and Ganasoundari, A. (1999). Modulation of glutathione and antioxidant enzymes by (Ocimum sactum) and its role in protection against radiation injury. Indian J. Exp. Biol., 37:262-268.

39) Navarro, J., Obrador, E., Carretero, J., Petschen, I., Avino, J., Perez, P. and Estrela, J. M. (1999). Changes in glutathione status and the antioxidant system in blood and in cancer cells associate with tumor growth in vivo. Free Radic. Biol. Med., 26:410 -418 .

40) Sahu, S. K., Oberley, L. W., Stevens, R. H. and Riley, E. F. (1977). Superoxide dismutase activity of Ehrlich ascities tumor cells. J. Natl. Cancer Inst., 58: 1125-1128.

41) Liu, J. G., Zhao, H. J., Yan-Juan, L. and Wang, X. L. (2010). Effect of selenium -enriched malt on VEGF and several relevant angiogenic cytokines in diethylnitrosamine -induced hepato carcinoma rats. Journal of Trace Elements in Medicine and Biology, 24:52-57. 
42) Garvin, S., Ollinger, K. and Dabrosin, C. (2006). Resveratrol induces apoptosis and inhibits angiogenesis in human breast cancer xenografic in vivo. Cancer lett., 231,113-122.

43) WU, C. F., Yang, J. Y., Wang, F. and Wang, X. $X$. (2013). Resveratrol: botanical origin, pharmacological activity and applications. Chinese journal of natural medicine, 11(1): 1-15.

44) Luo, H., Wang, L., Schulte, B. A., Yang, A., Tang, S. and Wang, G. Y. (2013). Resveratrol enhances ionizing radiation-induced premature senescence in lung cancer cells. Int. J. Oncol., 43(6): 1999-2006.

45) Apostolou, A., Stagos, D., Galitsiou, E., Spyrou, A., Haroutounian, S., Portesis, N., Trizoglou, I., Wallace Hayes, A., Tsatsakis, A. M. and Kouretas, D. (2013). Assessment of polyphenolic content antioxidant activity, protection against ROSinduced DNA damage and anticancer activity of Vitis vinifera stem extracts. Food Chem. Toxicol., 61;60-68.

46) Frombaum, M., Le Clanche, S., BonnefontRousselot, D. and Borderie, D. (2012). Antioxidant effects of resveratrol and other stilbene derivatives on oxidative stress and NO bioavailability: Potential benefits to cardiovascular diseases. Biochimie., 94:269-276.

47) Liu, J. G., Zhao, H. J., Yan-Juan, L. and Wang, X. L. (2010). Effect of selenium -enriched malt on VEGF and several relevant angiogenic cytokines in diethylnitrosamine -induced hepato carcinoma rats. Journal of Trace Elements in Medicine and Biology, 24:52-57.

48) Atten, M. J., Godoy-Romero, E., Attar, B. M., Milson, T., Zopel, M. and Holian, O. (2005). Resveratrol regulates cellular PKC alpha and delta to inhibit growth and induce apoptosis in gastric cancer cells. Invest. New Drugs, 23,111-119.

49) Kasiotis, K. M., Pratsinis, H., Kletsas, D. and Haroutounian, S. A. (2013). Resveratrol and related stilbenes: their anti-aging and antiangiogenic properties. Food Chem. Toxicol., 61:112120.

50) Zhang, A., Zhang, X., Tan, X., Cai, B., Ge, W., Dai, G. and Cai, J. (2015). Resveratrol rescued the TNF- $\alpha$-induced impairments of osteogenesis of bone-marrow derived mesenchymal stem cells and inhibited the TNF- $\alpha$-activated NF-кB signaling pathway. International Immunopharmacology, 26:409-415.

51) Zhang, F., Wei, Y., James, L. and Hargrove, P. (2002). Inhibition of TNF- $\alpha$ induced ICAM-1, VCAM-1 and E-selectin expression by selenium. Atherosclerosis, 161:381-386.

52) Liping, F., Liu, Q., Shen, L. and Wang, Y. (2011). Proteomic study on sodium selenite-induced apoptosis of human cervical cancer HeLa cells. Journal of Trace Elements in Medicine and Biology, 25:130-137

53) Oliinyk, B. V., Baraboi, V. A., Oliinyk, S. A. and Horchakova, N. O. (2001). Effect of splenosid on lipid peroxidation process and glutathione antioxidant system in rats exposed to fractionated radiation. Ukrainskii biokhimicheskii zhurnal, 73:73-77.

54) Gupta, A., Bhatt, M. L., and Misra, M. K. (2009). Lipid peroxidation and antioxidant status in head and neck squamous cell carcinoma patients. Oxidative medicine and cellular longevity, 2(2):68-72.

55) Ueda, T., Toyoshima, Y., Moritani, T., Ri, K., Otsuki, N., Kushihashi, T., Yasuhara, H. and Hishida, T. (1996). Protective effect of dipyridamole against lethality and LPx in liver and spleen of the ddY mouse after whole-body irradiation. International Journal of Radiation Biology, 69:199 204.

56) Abu-Zeid, M., Hori, H., Nagasawa, H., Uto, Y. and Inayama, S. (2000). Studies of methyl 2nitroimidazole-1-acetohydrox-amate (KIN-804) 2: effect on certain antioxidant enzyme systems in mice bearing Ehrlich ascites carcinoma. Biological and Pharmaceutical Bulletin, 23:195-198.

57) Hasegawa, T., Kaneko, F. and Niwa, Y. (1992). Changes in lipid peroxide levels and activity of reactive oxygen scavenging enzymes in skin, serum and liver following UVB irradiation in mice. Life Sci., 50:1893-1903.

58) Begum, N., Prasad, N. G., Kanimozhia, A. Q. and Hasan, S. (2012). Apigenin ameliorates gamma radiation-induced cytogenetic alterations in cultured human blood lymphocytes. Mutation Research, 747: $71-76$. 